\title{
Crashworthy Examination of a Newly Proposed Impact Attenuator Design: Experimental Testing and Numerical Analysis
}

\begin{abstract}
Laksmana Widi Prasetya, ${ }^{1}$ Aditya Rio Prabowo $\left(D,{ }^{1}\right.$ Ubaidillah Ubaidillah, ${ }^{1}$ Syamsul Hadi, Raymundus Lulus Lambang Govinda Hidajat, ${ }^{1}$ Tuswan Tuswan, ${ }^{2}$ and Ristiyanto Adiputra ${ }^{3}$
\end{abstract}

${ }^{1}$ Department of Mechanical Engineering, Universitas Sebelas Maret, Surakarta, Indonesia

${ }^{2}$ Department of Naval Architecture, Institut Teknologi Sepuluh Nopember, Surabaya, Indonesia

${ }^{3}$ Department of Marine Systems Engineering, Kyushu University, Fukuoka, Japan

Correspondence should be addressed to Aditya Rio Prabowo; aditya@ft.uns.ac.id

Received 16 June 2021; Accepted 19 August 2021; Published 24 September 2021

Academic Editor: Angelos Markopoulos

Copyright (c) 2021 Laksmana Widi Prasetya et al. This is an open access article distributed under the Creative Commons Attribution License, which permits unrestricted use, distribution, and reproduction in any medium, provided the original work is properly cited.

\begin{abstract}
The impact attenuator is a safety vehicle system designed to absorb the kinetic energy from a collision that is converted into deformation and ensures the deceleration level acting on the human body remains low. In this paper, we propose that the impact attenuator be fabricated with used cans, which are easy to obtain. Compared to fabricating cylinders through machining and other production processes using new material, the application of used cans may reduce production costs by approximately IDR 500,000 (USD 34.50) for one attenuator structure, while the attenuator still meets the weight criterion, i.e., it has to be light to improve acceleration and fuel efficiency. As a type of metal waste product, food cans are often fabricated from aluminum and other metal alloys. These products are widely used in our lives; if they are not recycled, they can potentially pollute the environment as waste. Given these problems and considering the use of environmentally friendly materials, lightweight used cans were chosen as materials for the proposed impact attenuator design. In the initial study, the verification and validation tests of the impact attenuator shell and used cans show good agreement between the numerical and experimental impact tests. The proposed impact attenuator design under the predetermined parameters showed that used cans of aluminum 6063 series can be recommended as an alternative material in this system.
\end{abstract}

\section{Introduction}

Student Formula is an international competition organized by the Formula Society of Automotive Engineers (FSAE), which challenges each team of students to conceptualize, design, and build a high-performance, small-model formula car. In the manufacturing of this formula car, safety and security factors are important, as they are regulated in detail in the FSAE rules [1]. Interest in comprehensive research on vehicle accident responses from various perspectives, including modeling and experimental studies, has increased [2]. In the automotive field, the vehicle industry continues to improve safety technologies and strategies, ranging from passive to active forms, to enhance passenger safety [3]. The impact attenuator is an essential structural component of a formula race car since it serves as a protective shield between the driver and the surface subject to impact loads [4]. The impact attenuator is designed to absorb the kinetic energy when collision energy is converted into a deformation to protect the vital parts behind the bulkhead from damage caused by shock loads. This attenuator is assembled in the front bulkhead of the vehicle because the most intensive load occurs in the front bulkhead position [5]. As explained in the rules, each team must design an impact attenuator with a wearable standard where the attenuator must absorb at least $7350 \mathrm{~J}$.

Some restrictions in the geometry of the impact attenuator during the manufacturing stage are set in the FSAE rules, such as a minimum length of $200 \mathrm{~mm}$ and a height of at least $100 \mathrm{~mm}$, and a width of $200 \mathrm{~mm}$ with a maximum distance of $200 \mathrm{~mm}$ to the front bulkhead. The anti-intrusion plate must have a thickness of $1.5 \mathrm{~mm}$ for solid steel and $4.0 \mathrm{~mm}$ 
for aluminum. In the case of an impact, the proposed design must not penetrate the front bulkhead and must not become a part of the bodywork structure. The other items that should not be damaged, such as the battery, main hoop, and hydraulic reservoir, must be positioned behind the bulkhead and cannot affect the attenuator zone [1].

In designing impact attenuators, several aspects need to be considered when choosing a material: cost, weight, reliability, and availability. The design must incorporate lightweight material [6]. In addition, the design must be built to absorb kinetic energy from a race car and minimize the deceleration acting on the human body in case of a collision [7]. To provide optimum safety to the driver, aluminum, composite, and other metal alloy foil are generally used $[4,8]$. Many substitute materials, such as used cans, including aluminum and other metal alloys in their elemental composition, can be used as an alternative. The main issue with beverage cans is that they are often recycled, but cans can pollute the atmosphere [9]. Another issue is the increasing use of aluminum for food and beverage packaging [10]. Beverage cans contain metal components, including 92-99\% aluminum, zinc, copper, manganese, magnesium, silica, etc. [11].

In this research, we aimed to identify an alternative use for discarded beverage cans. Waste cans are a low-cost compared to other materials widely used as impact attenuator materials. In essence, we aimed to provide potential solutions to mitigate the increasing can waste created by the growing use of cans as food or beverage packaging. From an economic point of view, compared to using a filling in the form of raw aluminum, which is shaped like a can or a cylinder, using a used can for an impact attenuator can reduce production costs by more than IDR 500,000 (approx. USD 34.50) because used cans have other advantages: they are easy to obtain. For this reason, used cans were chosen in this study to determine variations in the impact absorbers with an energy absorption capacity of $7350 \mathrm{~J}$. We aimed to reduce the costs of fabricating an impact attenuator and provide an alternative solution for recycling the aluminum waste in the surrounding environment.

\section{Impact Attenuator Technology}

2.1. Design Development. Many studies have been conducted on the manufacture of vehicle safety systems, and many developments have been achieved in terms of innovation in vehicle safety system design, such as the development of electric vehicles. The energy consumption of electric vehicles can be reduced by redesigning certain parts. We aimed to assess the ability of a square impact attenuation to absorb energy. Both metal and composite materials analyses were conducted to increase weight loss. An energy-damage approach was considered to determine the energy that is responsible for structural destruction. The best designs for electric frontal shock absorbers specialized for vehicles to absorb fixed impact energy are able to compare introduced metal and composite models.

Boria et al. [12] used a theoretical model that considers the energy during destruction. They analyzed various sce- nario, given the different absorption performance of metallic materials. Although simplifications were applied, this comparison revealed a reasonable level of model accuracy. This methodology was applied to determine the collision boxes to adopt in electric cars. The composite structure better meets the requirements compared to metallic materials. Hamidreza et al. [2] designed an optimal crash absorber. The study involved an experimental test of the axial collision and tilt angle of a tube. The numerical result indicated the good agreement with the experimental test. To enhance the energy absorption of various types of tubes, including square, rectangular, and circular tubes, a multi-design (MDO) methodology was developed. Measuring the risk of driver injury in a frontal accident scenario, Rising et al. [13] conducted an impact test with the SAE Formula car. In this research, the importance of absorbing the energy of an impact to protect the driver's head was emphasized using a proper headrest design. Later, Belingardi et al. [3] compared the impact attenuator as a completely independent and silver structure with the car body. The entire geometric model of the vehicle construction was created in CATIA 3-D in accordance with the 2008 SAE rules. In the first half of the simulation, both structures exhibited the same crushing behavior and the same energy absorption rate. In contrast, the skeletal structure's attenuator impact deformed more at the end of the simulation than the independent frame.

Using another method, the cost of developing and testing a new safety-related design can be reduced using accident simulation [3]. Vehicle safety conditions can be assessed through simulation under actual conditions $[13,14]$. The finite element method (FEM) is one of the powerful approaches for determining the destruction conditions of impact attenuators. Several scholars have performed different simulation tests to determine the effects of impact on the attenuator conditions. Williams et al. [14] conducted an impact test using the front of the Caterham sports car 7 using ANSYS LS-DYNA 3D code. The comprehensive impact event and the contribution of each component were determined. Heimbs et al. [7] examined the cone collision condition of the impact structure of F1 racing cars, using LS-DYNA to control the modeling of composite materials. The numerical findings were compared to the crash test data in terms of crush, energy absorbed, and deceleration rates.

\subsection{Design Novelty and Comparison to Existing Designs.} Before conducting this research, several studies of impact attenuators reported designs similar to the latest designs. Obradovic et al. [15] conducted analytical, computational, and experimental investigations on energy-absorbing composite structures with simple tubular shapes and subsequently with more complicated geometries. Composite material characterization testing and tube crushing experiments were conducted to set the appropriate parameters for the numerical models. As a result, the absorbed energy and actual crushing could be approximated with an accuracy of about $90 \%$. An experimental test of the crashworthiness of the impact attenuator design revealed that the nose cone structure is stable, with flat, almost constant force vs. 
displacement curves and an acceleration limit of less than $20 \mathrm{~g}$. This result conforms to the criteria of the SAE 2008 standard.

Boria et al. [8] described an approach to designing an impact attenuator using composite material with a thinwalled square frustum shape. The procedure consists of a theoretical approach that considers the energy contributions during axial crushing, analytically defining the external load as a function of three factors that must be minimized. The method can predict the mean load and total crushing of a square frustum formed of composite if the material parameters are known.

Significant distinctions differentiate the two prior studies and the current design: our impact damper uses a filler composed of a used sardine can. Then, using a square frustum-shaped design, aluminum is employed as the shell of the impact attenuator. There are no holes on the sides of the shell to improve energy absorption. Only the shell is collision-absorbing, as it is not composed of rigid material.

\section{Structural Crashworthiness}

3.1. Terminological Definition. The definition of crashworthiness, in general, is the resistance of a structure to collision. In the automotive sector, nearly all car manufacturers conduct crashworthiness tests on their newest vehicle type before selling them to consumers. For example, Subaru recently conducted crashworthiness tests for its latest car model [16]. Two criteria must be met by a car to meet crashworthiness: (i) the passenger compartment is not distorted, and no exterior objects that might endanger passengers are introduced; (ii) a minimum the deformation distance in front of the passenger compartment to prevent extreme injury to passengers.

In cars, to protect the passenger compartment due to a front-end collision, a bumper system is installed to that absorbs collision energy by deforming due to a crash. The bumper system can reduce damage to the passenger compartment, preventing injury to the passenger and slowing the passenger's body at a safe level. The bumper system consists of frontal and longitudinal bars. When a frontal collision occurs, the frontal bar transmits the energy of the crash. The power is then absorbed longitudinally using plastic deformation in the form of repeated longitudinal folds.

3.2. Absorption of Energy. The total energy absorbed $(E A)$ is the sum of the entire product of the force of disintegration and displacement represented by the force-displacement curve. The total energy absorption is described by the area under the force-displacement curve [17]. This parameter may be analytically computed using.

$$
E A(d)=\int_{0}^{d} F(\delta) d \delta
$$

3.3. Crushing Force. The mean crush force $(P m)$ is calculated by dividing the energy absorption $(E A)$ by the change in maximum displacement [17]. This parameter may be computed using.

$$
P m=\frac{E A}{\delta}
$$

The total energy absorption capacity is determined by the mean crush force $(P m)$. To investigate the geometry or material discrepancy, balanced complete energy absorption by mass is necessary, and it is achieved through calculating specific energy absorption as

$$
S E A=\frac{E A}{m}
$$

The crush force efficiency (CFE) is used to demonstrate the crashworthiness capability of structural components. The parameter is defined as the ratio of mean crushing force to maximum peak force [18].

$$
C F E=\frac{P m}{P \max }
$$

3.4. Pioneer Works in Vehicles and Transportation. In a series of critical vehicle structures, such as vehicle frames, helicopter sub-floors, and highway dividers, crashworthiness was studied in the field of plastic structure deformation. The main objective of these studies is to protect individuals against injuries due to impacts, crashes, and collisions [19]. Many scholars have undertaken extensive technical work on the various geometries of the crash box. By evaluating several different geometrical factors, the influence of design geometry on crash energy absorption was explored to assess the effect on the energy absorption capacity of the crash box.

The energy absorption characteristics of glass-fiberreinforced plastic (GFRP) crash boxes with different geometric shapes exposed to axial crush loading were evaluated by Hussain [20]. The comparison of the crash outputs demonstrated that the increasing order of the energy rate absorbed by the thin-wall structure with square, cylindrical, hexagonal, and decagonal shapes. Nia et al. [21] evaluated a significant number of tubes composed of aluminum alloy in various cross-sectional configurations. They found that absorbed energy per unit mass was the highest for cylindrical tubes for the same loading type (quasi-static loading).

Weight-saving demands have prioritized the design and the materials of car bodies and assembly parts for vehicle manufacturers [12]. Several researchers have evaluated the absorbing energy performance of different materials. Three different material categories have been investigated regarding crashworthiness: metal/alloy, composites, and a hybrid of composites-metal/alloy. In the category of metal/alloy, investigations mainly focused on the major steel and aluminum materials. According to Reyes et al. [22], steel is usually for various reasons: prior findings with the same material are available to enable comparison, the significant use of steel in car body structures, convenient accessibility, and affordability. Conversely, aluminum is a lightweight yet robust material that has attracted the curiosity of experts trying to 
examine its crashworthiness. The behavior of several types of composite materials as a crash box has been extensively investigated; the brittleness of composite materials resulted in the development of composite-metal/alloy hybrids [12].

Understanding the crash behavior under various workloads helps to design the crash absorber structure of a car. The four car crash loads are axial, oblique, lateral, and bending loading [23]. Axial and oblique loading conditions are strongly related to the structure of the crash box. The tube is compressed in parallel to the longitudinal axis of the lateral loading condition. This kind of loading for car bumpers is usually examined and positioned longitudinally at the front of the vehicle. The axial and oblique crash loads can be evaluated in an almost quasi-static or dynamic environment to explore the performance of crash-absorbing members. Various test settings are used to understand how the tested structure is influenced by crushing speed and energy [24].

\section{Foundation of Failure Pattern}

4.1. Plate/Shell Tension. In [25], a theoretical methodology was created to examine the response and predict the permanently deformed profile of an arbitrarily shaped ductile plate exposed to significant static or dynamic loads causing plastic strain. The material was assumed to be a rigid, perfectly plastic with a yield stress $\sigma_{0}$ and a uniform thickness $H$. The governing equations for impact loading can be simplified as

$$
\begin{aligned}
-G \ddot{W} \dot{W}-\int_{A} \mu \ddot{w} \dot{w} d A \\
=\int_{A}\left\{\left(M_{r}+w N_{r}\right) \dot{k}_{r}+\left(M_{\theta}+w N_{\theta}\right) \dot{k}_{r}\right\} d A \\
\quad+\sum_{m=1}^{n} \int_{C_{m}}\left(M_{r}+w N_{r}\right)\left(\frac{\partial \dot{w}}{\partial r}\right)_{m} d C_{m}+\sum_{u=1}^{v} \int_{C_{u}} Q_{r}(\dot{w})_{u} d C_{u}
\end{aligned}
$$

The basic methodology was adopted in this context to estimate the dynamic response of plastic beams and plates in circular plates exposed to dynamic pulses and blasts [25-27], and rigid mass in the central span for beams and round and square plates [21, 28]. The transverse shear in Eq. (5) was not investigated further for the last term since significant ductile deformations were analyzed without material failure or perforation. As a result, the yield condition is composed of four common stresses $\left(M_{r}, M_{\theta}\right.$, $N_{r}$, and $N_{\theta}$ ). The deformation profile is composed of rigid areas divided by a plastic hinge; then, the proper yield conditions in Figure 1 govern the plastic flow at the hinge line. The exact yield criterion is circumscribed by a square yield condition (maximum normal stress yield criterion).

The admissible transverse velocity field in Figure 2 is assumed to govern the response of the rectangular plate $(2 L \times 2 B)$ in Figure 3, which has a moment resistance $m M_{0}$ around the supports ( $m=0$ and 1 describe the supported and the fully clamped cases, respectively, but intermediate cases $(0<m<1)$ are included in the analysis). It was assumed that the mass strikes the rectangular center of the

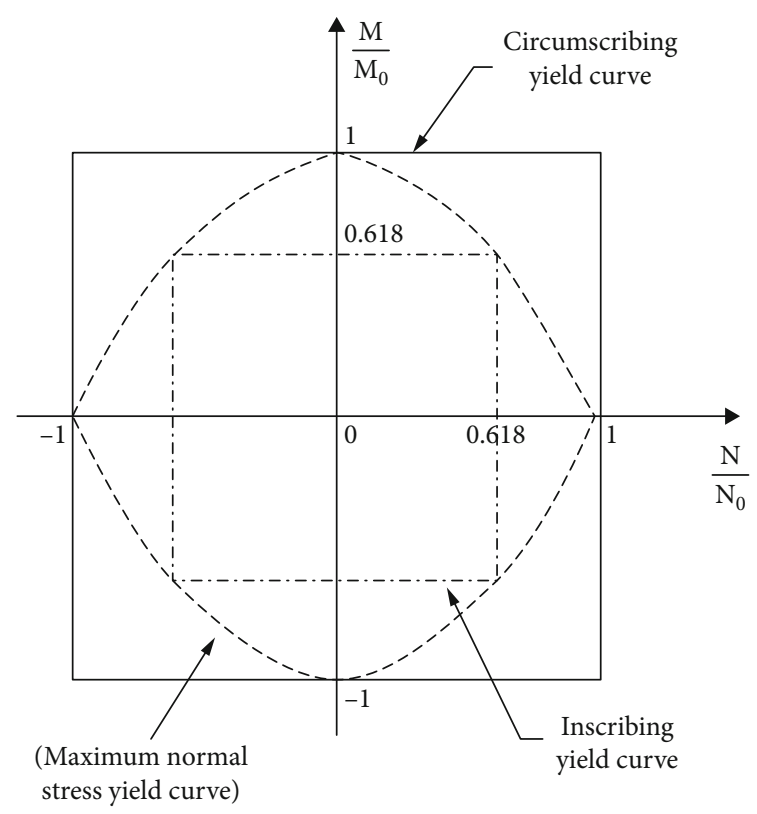

FIgURe 1: Yield conditions at plastic hinged lines developed in the rectangular plate (including support for $\mathrm{m} \neq 0$ ).

plate, has a negligible cross-section relative to the size plate $B$ and $L$, and provides a response that can be expressed by Eqs. (6) and (7) defined by the transverse velocity profile in Figure 2.

$$
\begin{aligned}
& \dot{w}=\dot{W}(1-x / L), 0 \leq x \leq L, 0 \leq y \leq B x / L \\
& \dot{w}=\dot{W}(1-x / B), 0 \leq x \leq y L / B, 0 \leq y \leq B
\end{aligned}
$$

For the quadrant that has positive $\mathrm{x}$ and $\mathrm{y}$ values, the behavior of this quadrant is identical to the other three quadrants based on concepts of double symmetry.

Figure 2 shows a transverse velocity profile that requires plastic hinges at the diagonals and the supports of a rectangular plate (unless $m=0$ ). For a hard, perfectly plastic material, the interior regions remain rigid. Hence the integral for continuous deformations in Eq. (7) does not affect internal energy dissipation. As a result, Eq. (5) is rewritten as Eq. (8) are as follows.

$$
-G \ddot{W} \dot{W}-\int_{A} \mu \ddot{w} \dot{w} d A=\sum_{m=1}^{r} \int_{l_{m}}(M+N w) \dot{\theta}_{m} d l_{m}
$$

For a flat, rigid, perfectly plastic plate that is deformed by stationary, straight, plastic hinges into many rigid zones, the membrane force and bending moment act on a plane that passes through a hinge and is transverse to the mid-surface of a plate. When Eq. (8), for the impact in Figure 3, is combined with Eqs. (6) and (7) for the transverse velocity field and the square yield condition in Figure 1, the following equation is obtained:

$$
\ddot{W}+\alpha^{2} W=-(1+m) H \alpha^{2} / 2
$$




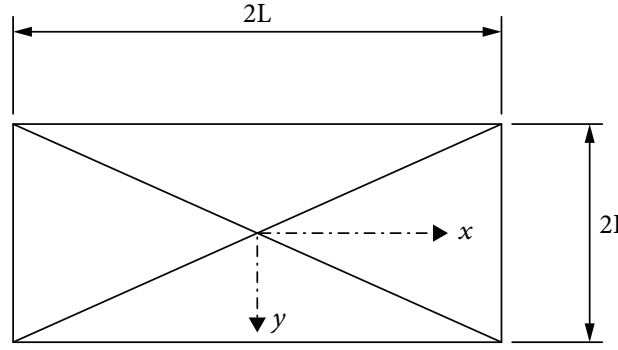

(a)

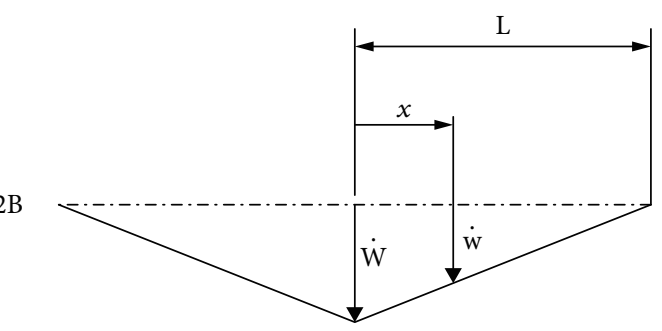

(b)

Figure 2: Pyramidal-shaped transverse velocity field for a rectangular plate struck at the center: (a) plan view of plastic hinge lines, (b) side view of pyramidal-shaped transverse velocity.

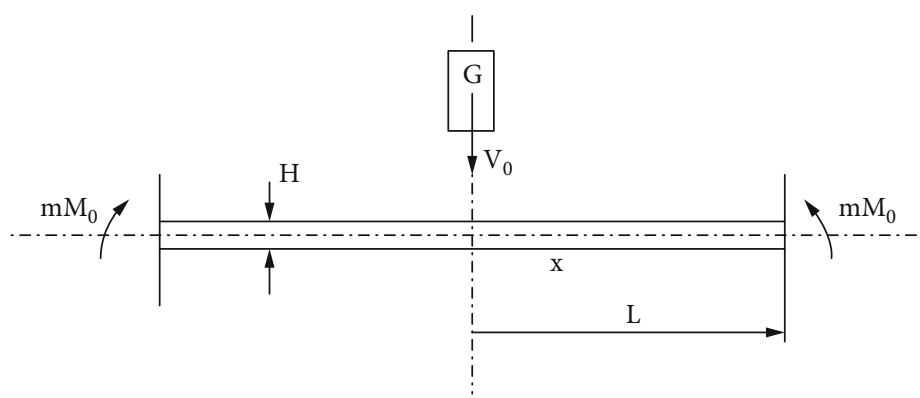

FIgURe 3: A rectangular plate with a length struck at the center by a rigid mass $G$ traveling at an impact velocity $V_{0}$. The bending resistance around the four supports is $m M_{0}$, where $0 \leq m \leq 1$ and $M_{0}$ is the plastic limit moment per unit length of the plate cross-section.

where

$$
\begin{gathered}
\alpha^{2} \frac{12 M_{0}\left(1+\beta^{2}\right)}{\mu H L^{2}(1+6 \gamma) \beta^{2}} \\
\beta=\frac{B}{L} \\
\gamma=\frac{G}{4 \mu B L} .
\end{gathered}
$$

It is necessary to maintain the linear momentum at $t=0$ :

$$
\begin{aligned}
G V_{0}= & G W+4 \mu \int_{0}^{L} \int_{0}^{\frac{B x}{L}} \dot{W}\left(1-\frac{x}{L}\right) d x d y \\
& +4 \mu \int_{0}^{L} \int_{0}^{\frac{B x}{L}} \dot{W}\left(1-\frac{y}{B}\right) d x d y
\end{aligned}
$$

or

$$
\dot{W}=V_{0} /(1+1 / 3 y)
$$

Then, Eq. (15) has a general solution:

$$
W=A \sin \alpha t+B \cos \alpha t-(1+m) H / 2
$$

The values of $\mathrm{A}$ and $\mathrm{B}$ are obtained from the initial conditions at $t=0$; namely, $w=0$, and $W$ can be denoted by Eq. (16).

$$
W=\frac{V_{0}}{\alpha(1+1 / 3 y)} \sin \alpha t+\frac{(1+m) H}{2} \cos \alpha t-\frac{(1+m) H}{2}
$$

Now differentiating Eq. (16) concerning time provides the transverse velocity $\dot{W}$ from the duration of motion $T$ when $\dot{W}=0$, or

$$
\tan \alpha T=\frac{2 V_{0}}{(1+1 / 3 y)(1+m) \alpha H}
$$

Finally, Eqs. (8) and (9) represent the dimensionless maximum permanent transverse displacement, which can be denoted as:

$$
\frac{W_{f}}{H}=\frac{(1+m)}{2}\left[\sqrt{\left\{1+\frac{12 \beta \Omega \gamma(1+6 \gamma)}{\left(1+\beta^{2}\right)(1+m)^{2}(1+3 \gamma)^{2}}\right\}}-1\right]
$$

If the striking mass $G$ is heavy compared to the plate mass, then $\gamma^{\prime \prime} 1$, and Eq. (19) reduces to:

$$
\frac{W_{f}}{H}=\sqrt{\left\{1+\frac{12 \beta \Omega}{\left(1+\beta^{2}\right)}\right\}}-1
$$

where

$$
\Omega=\frac{G V_{0}^{2}}{4 \sigma_{0} H^{3}}
$$

With $m=1$, for the fully clamped scenario, Eq. (19) reduces the corresponding equation for a square plate with 
$\beta=1$. Eq. (17) and (18) provide the assumptions for a supported rectangular plate impacted by a rigid mass with $m=0$.

4.2. Concertina Tearing. The existence of two distinct failure mechanisms was demonstrated by all scale experiments on wedge indentation into metal plates. Plates failed in the case of sharp wedges with a slight tip angle by developing a longitudinal cut at or ahead of the wedge's tip, followed by the formation of two curls at the wedge's wake. When the wedge was blunt, and the tip angle was large and the same plates failed by folding in front of the wedge and tearing at remote boundaries. This is referred to as concertina tearing. Wierzbicki [27] investigated concertina tearing in 1994 and discovered that the tearing force has a formula as follows:

$$
F_{c o n}=5.04 \sigma_{0} t^{1.67} b^{0.33}+\frac{8}{3} R_{c} . t
$$

with a range for the specific work of fracture of mild steel: $R_{c}=300 \sim 1000(\mathrm{~N} / \mathrm{mm})$.

Deformation may occur in several folds. Observations from many tests demonstrated that the webs rupture during the second fold. The average crushing force for concertina tearing is given in Eq. (22) by adding the contributions from the first folded lobe and the second newly crushed lobe, as follows:

$$
F_{c o n}=(2.435+4.33) \sigma_{0} t^{1.67} b^{0.33}=6.77 \sigma_{0} t^{1.67} b^{0.33}
$$

4.3. Plate Folding. Plate folding is a form of deformation that occurs when a straight plate is given a load that exceeds the

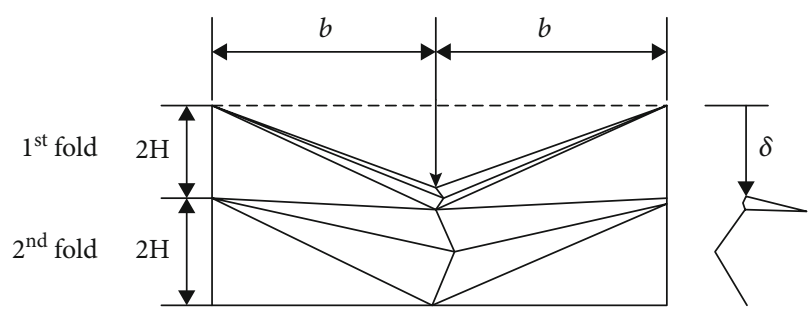

FIGURE 4: Subsequent folding of web crushing.

yield limit of the material. The crushing mode is illustrated in Figure 4. The double fold is expected to be the same as the first fold. The behavior of subsequent folds is similar to that of a centrally indented beam or transverse load [29]. Equation Eq. (23) is used to calculate the resistance force of the first folded web.

$$
F_{1}=4.62 \sigma_{0} t H \frac{\delta-2 H}{b}
$$

The crushing force for the second folding process is written as Eq. (24) when the resistance of the first folded web is considered.

$$
F=4.33 \sigma_{0} t^{1.67} b^{0.33}+4.62 \sigma_{0} t H \frac{\delta-2 H}{b}
$$

The crushing force can also be established at the third, fourth, fifth fold, etc. In short, the web crushing resistance force can be stated as:

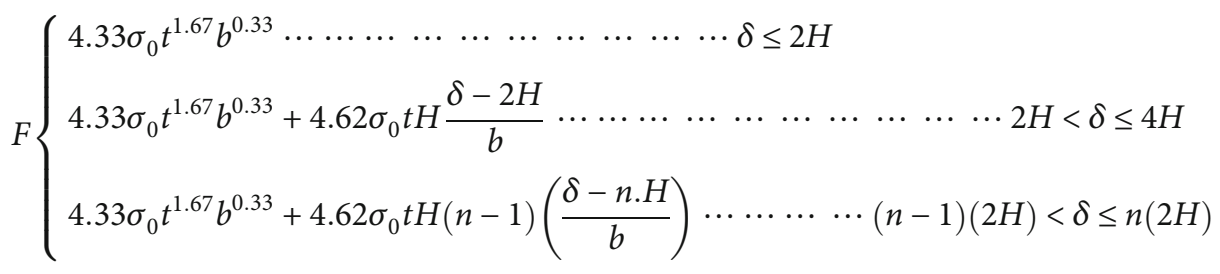

With several folds, the web rupture in the $n_{0}$ th fold becomes Eq. (26) if its penetration is larger than the critical penetration.

$$
n_{0}=\operatorname{Int}\left[\frac{\delta_{c}}{2 H}\right]+1=\operatorname{Int}\left[0.6\left(\frac{b}{t}\right)^{0.33} \sqrt{2 \varepsilon_{c}}\right]+1
$$

4.4. Axial Crushing. A static axial load applied to a thinwalled cylindrical shell or tube is illustrated in Figure 5 [30]. In many practical contexts, thin-wall circular tubes are employed to absorb impact energy. The research regarding axial influence was later conducted by considering the structural crashworthiness of rail coaches with thin-walled circular and square tubes.

The total amount of energy absorbed during the configuration of one full wrinkle in a thin-walled circular tube in Figure 6 is:

$$
D_{T}=4 \pi M_{0}(\pi R+l)+2 \pi \sigma_{0} l^{2} H
$$

The equation can also be written as

$$
D_{T}=2 \pi \sigma_{0} H^{2}(\pi R+l) / \sqrt{3}+2 \sigma_{0} l^{2} H
$$




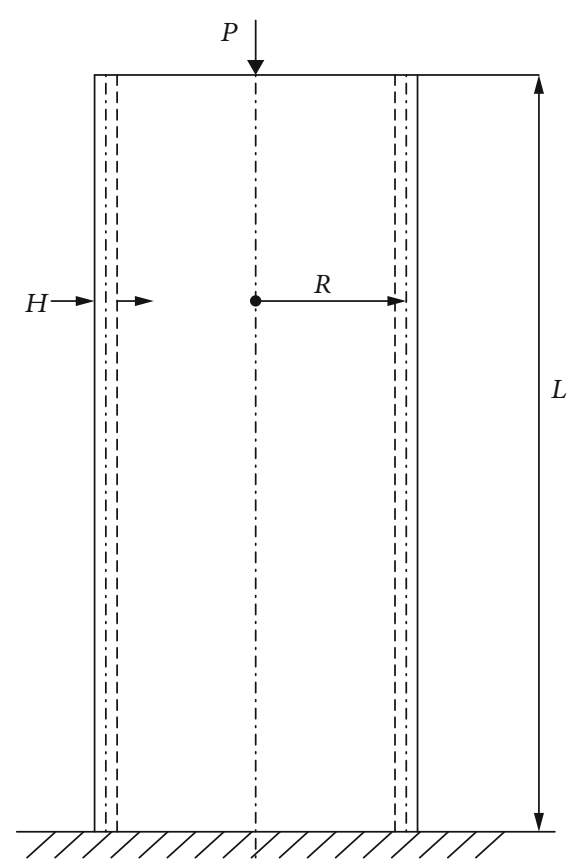

Figure 5: An axial force $P$ was applied to a thin-walled cylindrical shell.

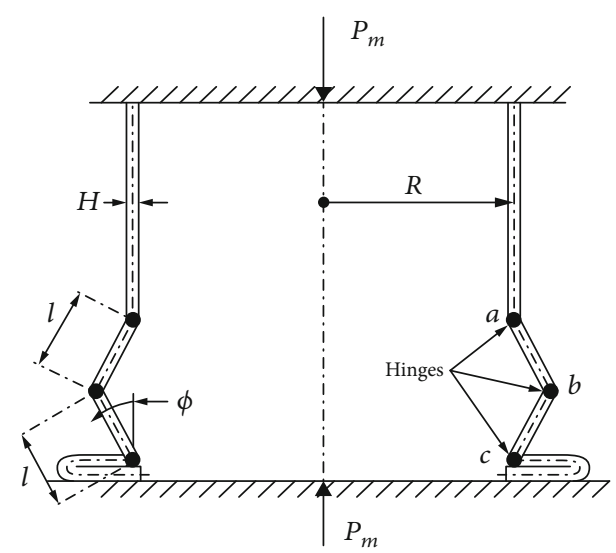

FIGURE 6: Idealized axisymmetric or concentrated crushing mode for axial compression of a cylindrical shell.

Theoretical analysis showed that the mean crushing force for a tube with convolutions that form internally instead of externally is

$$
\frac{P_{m}}{M_{0}}=4(3)^{\frac{1}{4}} \pi^{\frac{3}{2}}\left(\frac{R}{H}\right)^{\frac{1}{2}}-2 \pi
$$

which offers a reasonable approximation to the actual crushing force:

$$
P_{m}=2(\pi H)^{\frac{3}{2}} R^{\frac{1}{2}}\left(\frac{\sigma_{0}}{3^{1 / 4}}\right)
$$

\section{Mathematical Formulae and Algorithm}

5.1. Von Mises Stress. The von Mises yield criterion states that if the loaded material of stress exceeds or is equivalent to the performance yield limit [31], yields are achieved. Therefore, the von Mises yield criterion is commonly rewritten as:

$$
\tau_{v} \geq S_{y}
$$

The von Mises stress is a theoretical value that compares three-dimensional stress in general with the uniaxial stress level. In this case, von Mises stress can be written as Eq. (32) where $z, r$, and $t$ are the axial, radial, and tangential stresses, respectively.

$$
\sqrt{\frac{\left(\tau_{z}-\tau_{t}\right)^{2}+\left(\tau_{t}-\tau_{r}\right)^{2}+\left(\tau_{r}-\tau_{z}\right)^{2}}{2}}=\tau_{v}
$$

5.2. Explicit FE Methodology. The impact attenuator crash is classified in a nonlinear dynamic event requiring the appropriate calculative method for resolving its almost-limitless scenario [23, 32-34]. Nonlinearity is integrated into the analysis, as underlying principles of linear analysis are contradicted by materials and structures that surpass its yield limit. Depending on the time, the dynamic characteristic is considered to change gradually. The explicit technique is recommended to solve phenomena with these requirements since certain assumptions are beneficial, such as the subject is a lumped mass matrix, and simple inversion is required. Uncoupled mathematical equations can be solved directly, so a convergence check is not required. When all nonlinear variables (including contact) are included in the internal force vector, no inversion on the stiffened matrix is necessary. To maintain the stability limit, a small time step is necessary, which corresponds to the short time process of an impact attenuator collision. The formulation of explicit time integration is as follows:

$$
\begin{aligned}
\{a t\} & =[M]^{-1} \leq\left(\left\{F_{t}^{\text {ext }}\right\}-\left\{F_{t}^{\text {int }}\right\}\right) \\
F^{\text {int }} & =\sum\left(\int_{\Omega}\left(B^{T} \sigma_{n} d \Omega+F^{h g}\right)+F^{c o n t}\right) \\
\left\{V_{t+\frac{\Delta t}{2}}\right\} & =\left\{V_{t-\frac{\Delta t}{2}}\right\}+\left\{a_{t}\right\} \Delta t_{t} \\
\left\{U_{t+\Delta t}\right\} & =\left\{U_{t}\right\}+\left\{V_{t+\frac{\Delta t}{2}}\right\} \Delta t_{t+\Delta t 2} \\
\left\{X_{t+\Delta t}\right\} & =\left\{X_{0}\right\}+\left\{u_{t+\Delta t}\right\}
\end{aligned}
$$

\section{Experimental Testing}

6.1. Test Profile. Compressive testing was conducted using a universal testing machine (UTM) on a specimen consisting of a shell of an impact attenuator and a used can. The experimental tools used in this test case are illustrated in Figure 7, and the dimensions of the impact attenuator and shell cans are described in Figure 8. During the compressive test shown 


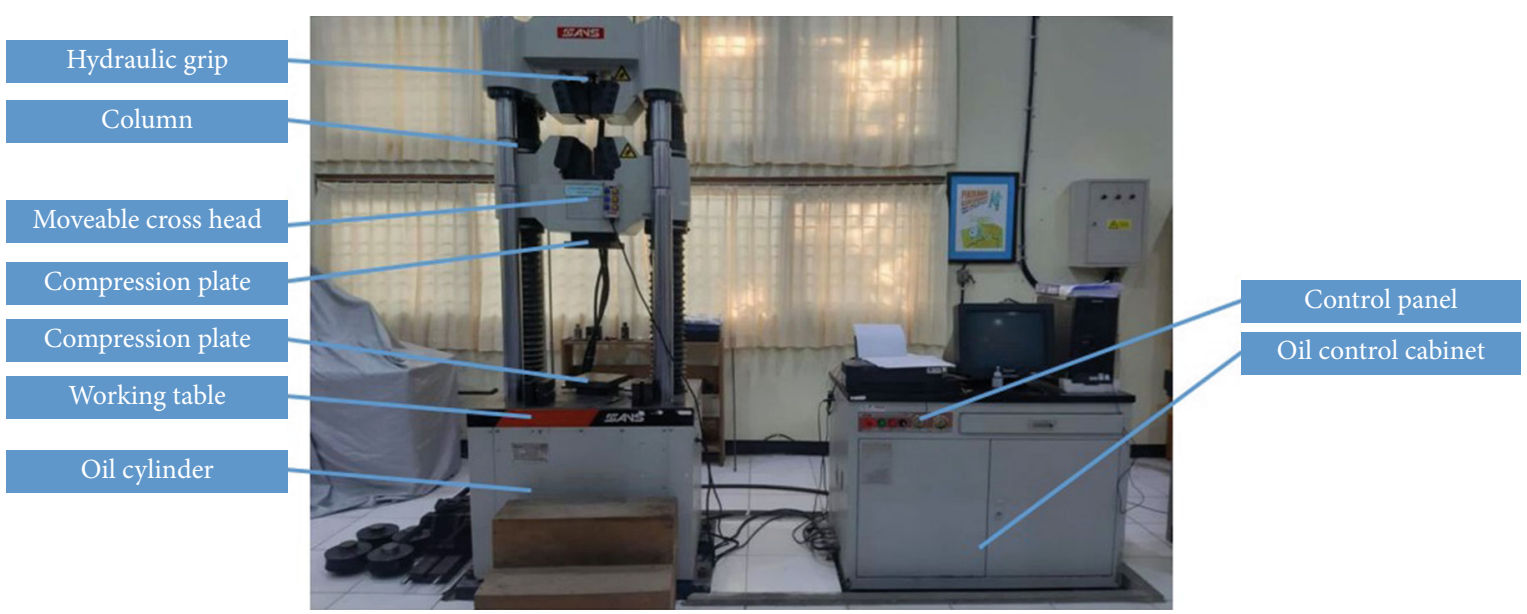

Figure 7: The universal testing machine (UTM) used in the experiments.

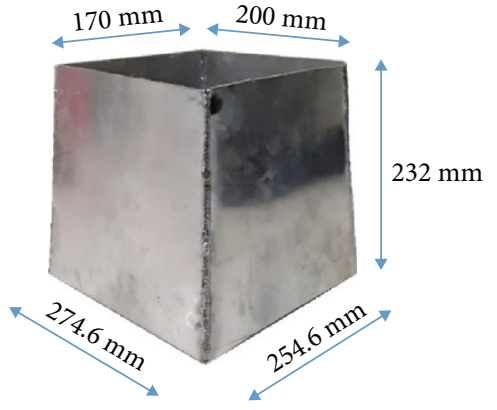

(a)

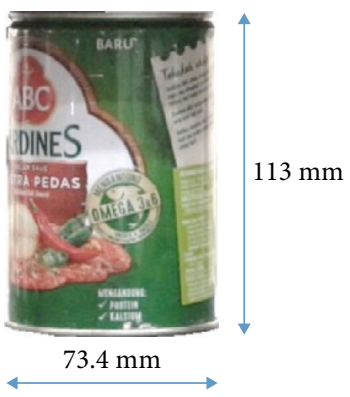

(b)

Figure 8: Dimensions of the (a) impact attenuator and (b) used cans.

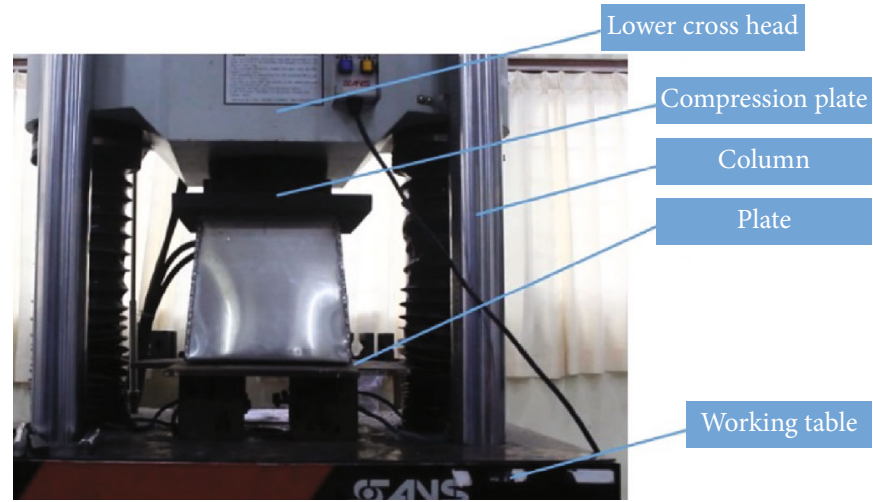

(a)

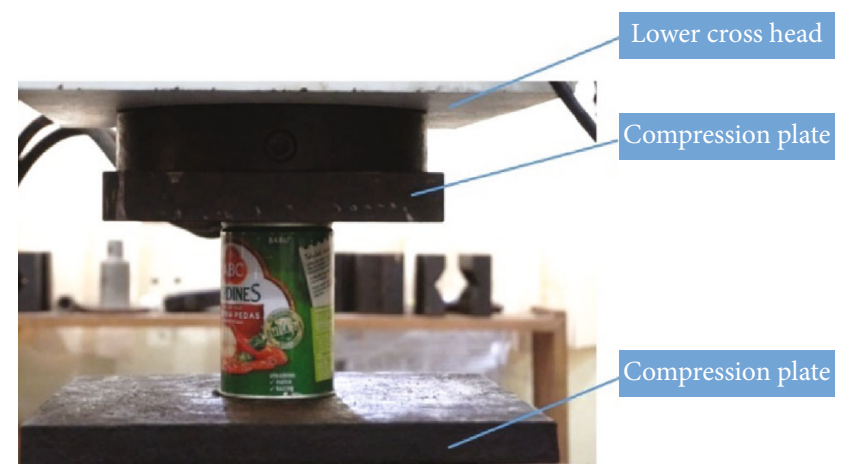

(b)

Figure 9: Experimental testing setup for the (a) shell of the impact attenuator and (b) used cans.

in Figure 9, both the impact attenuator and used cans were placed in the rectangular plate to fix the position. The compressive test was conducted by compressing the specimens using a rectangular compressive plate moved by a moveable crosshead. A video of the test object as a material for analyzing the deformation shape during the test was recorded. The result of the compressive test was obtained by plotting the crushing force and internal energy curves of both the impact attenuator and the used cans. The results of the experimental test, especially for the table, were used to the verify simulation results, as described below.

6.2. Verification: Finite Element Analysis Vs. Experimental Laboratory Test. The verification test was used to validate the finite element model. In the verification, the crushing force and internal energy results of the experimental test 


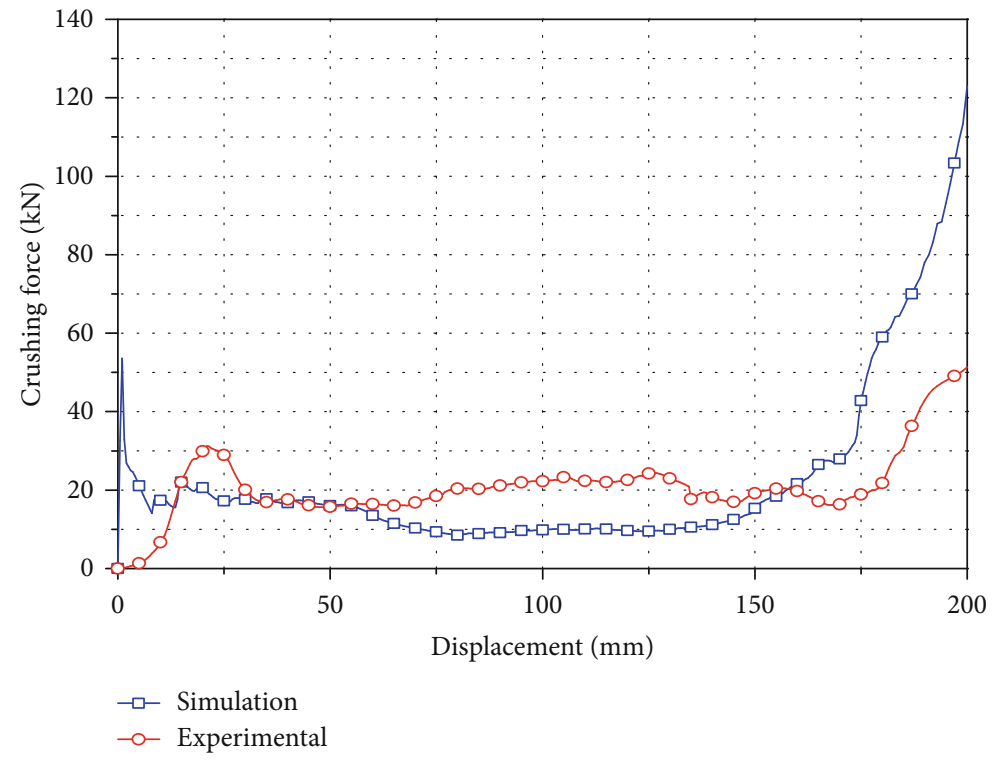

(a)

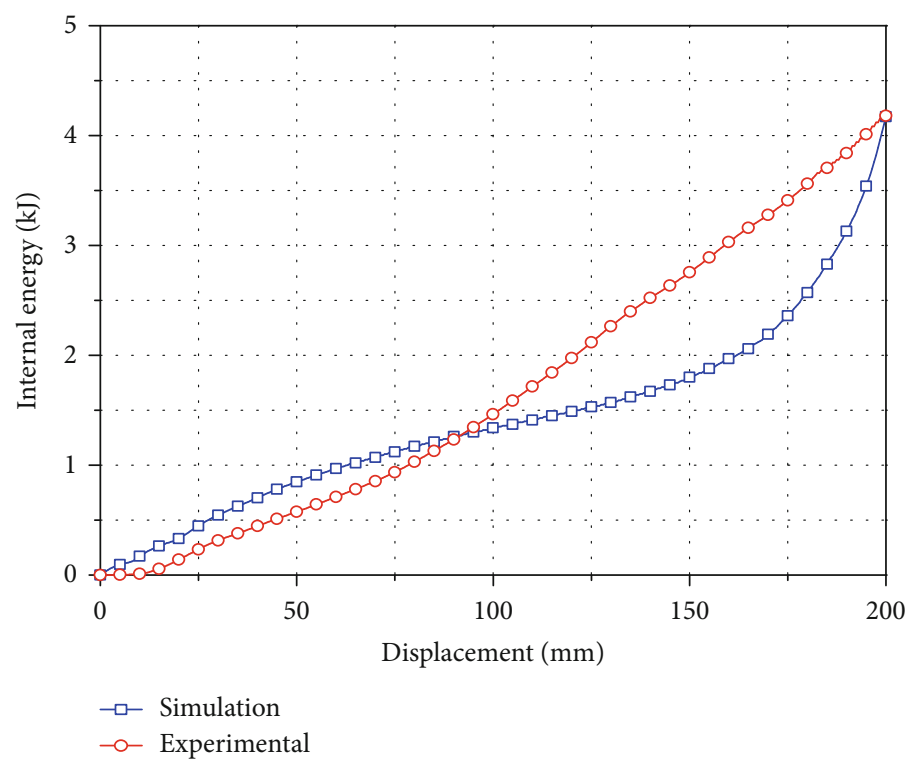

(b)

Figure 10: The validation test of (a) crushing force and (b) internal energy in the shell impact attenuator.

were compared to the simulation results obtained with ANSYS LS-DYNA software with an expected error limit of $5 \%$. The first verification test was conducted by comparing the experimental and numerical results of the crushing force and internal energy of the impact attenuator, as shown in Figure 10. Figure 10(a) shows that the crushing forces obtained by the experimental and numerical tests are a good agreement. We found that both results have a similar curve, although the crushing force of the simulation test has a larger value at the end of the curve. The validation test of the impact attenuator using internal energy is shown in Figure 10(b); the two curves have a similar curve pattern, where the simulation test begins with an increase in load and then immediately drops. The curve tends to experience stable fluctuations. However, the curve has a high growth
TABLE 1: Comparison of internal energy between experimental and simulation results.

\begin{tabular}{lcccc}
\hline Internal energy & Unit & Simulation & Experiment & Error \\
\hline Used cans & Joule & 54.6693 & 53.9473 & $1.3 \%$ \\
Shell of impact attenuator & Joule & 4173.48 & 4180.25 & $0.2 \%$ \\
\hline
\end{tabular}

because, when it reaches the displacement, the impact skin forms stacked folds and creates a more severe condition in the material so that the load has a higher value, as shown in Figure 10(a). Although the shapes of the curve are not too similar, both results of the internal energy value met the error requirement of being below 5\%, as shown in Table 1. The curve appears somewhat different because in 

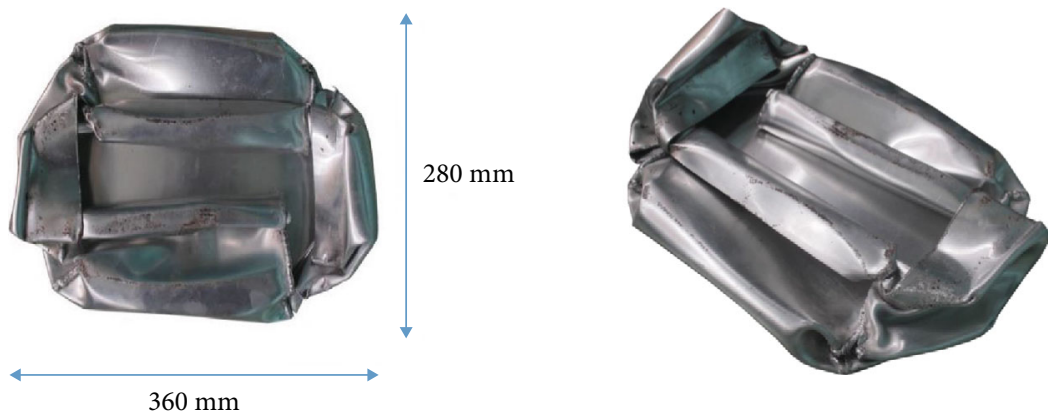

(a)
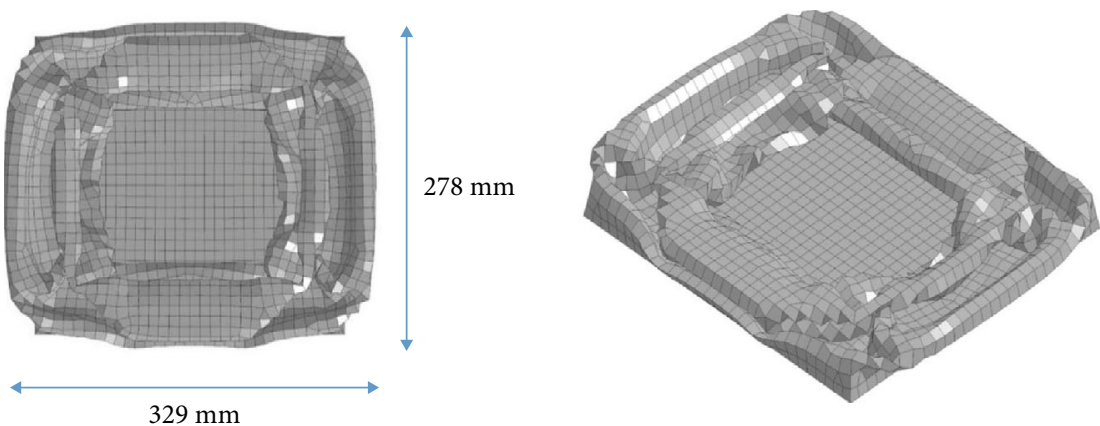

(b)

FIGURE 11: Comparison of deformation shape of impact attenuator shell: (a) experimental test and (b) nonlinear FE simulation.

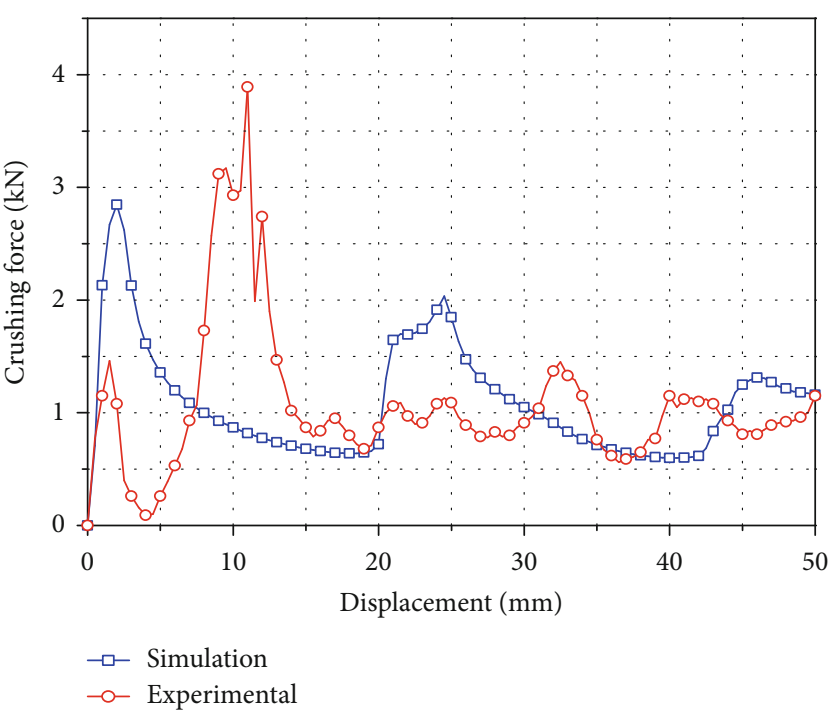

(a)

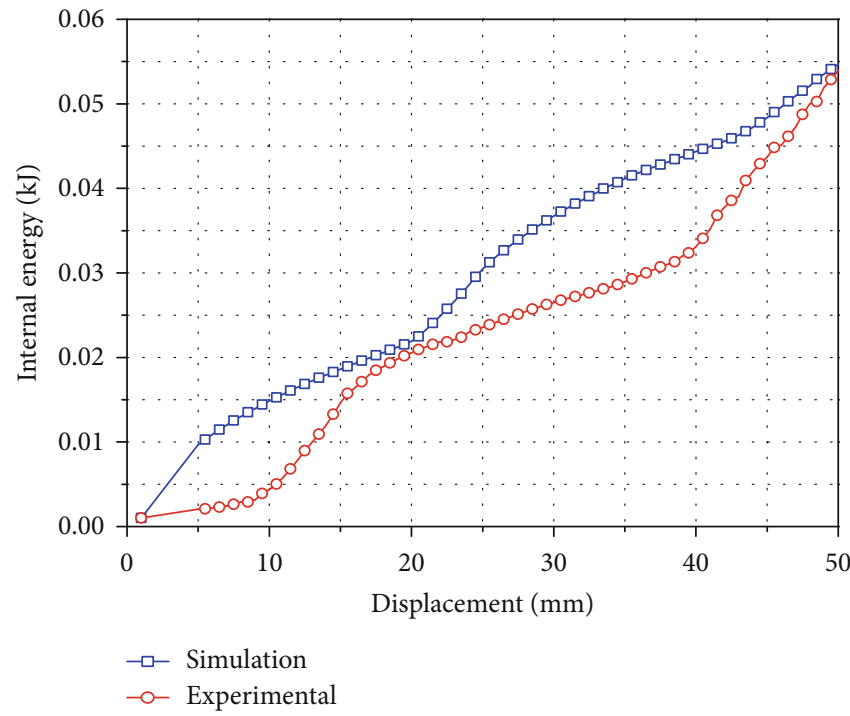

(b)

FIGURE 12: The validation test of (a) crushing force and (b) internal energy in the used cans.

experimental testing, the impact skin of the impact attenuator had a less-than-perfect weld. When the pressure was applied to the skin, it caused stress concentration at the welding angles. We also observed that the impact attenuator tore at corners at the end of the test. The deformation shape due to impact loading between experimental and numerical simulations is compared in Figure 11.

The comparison of the experimental and numerical test results of used cans is illustrated in Figure 12. In
Figure 12(a), the crushing force of both simulations shows that the two curves have an up-and-down pattern that begins with the two curves rising; when the displacement approaches $5 \mathrm{~mm}$, the curve decreases. Then, the two curves change in value, up and down, ending at a displacement of $50 \mathrm{~mm}$. Although not precisely the same, the up-and-down patterns on the chart are similar. For the comparison of internal energy (Figure 12(b)) of used cans, the internal energy increases with the increase in displacement. Although we be 


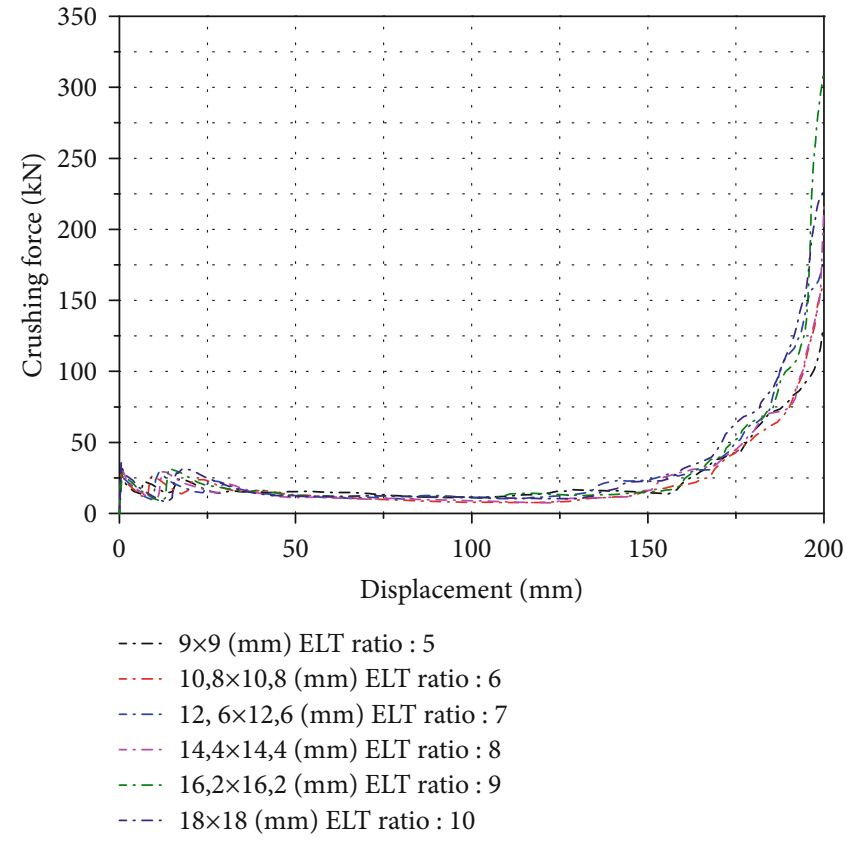

(a)

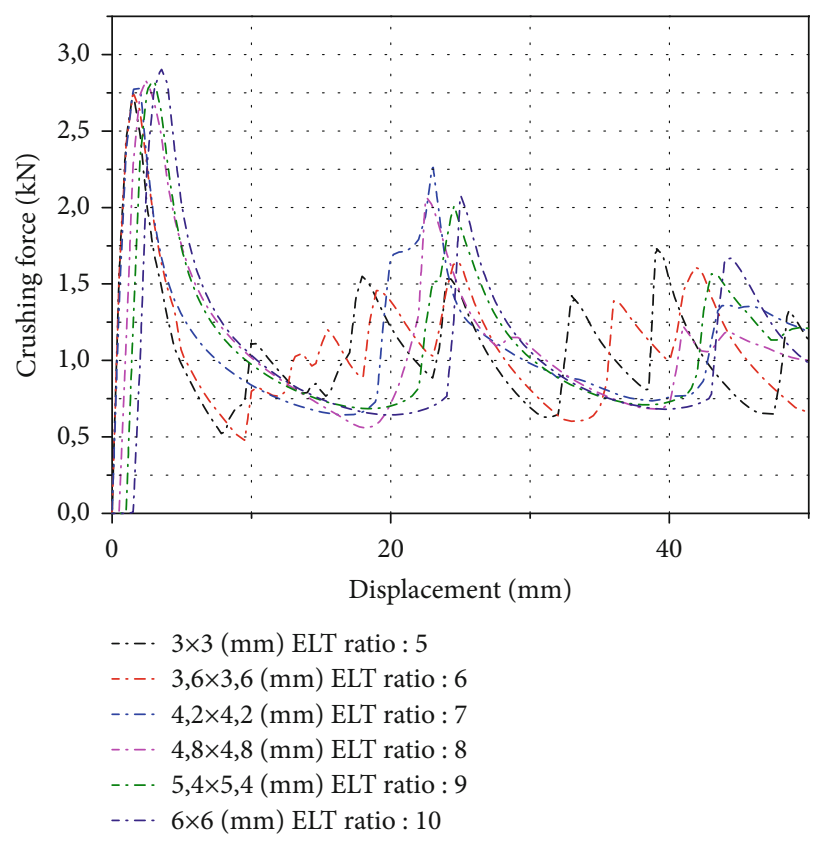

(b)

FIGURE 13: The crushing force with a different mesh size between (a) the shell of the impact attenuator and (b) used cans.

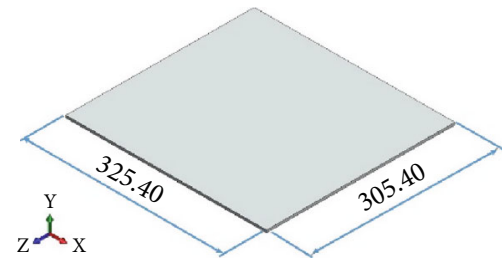

(a)

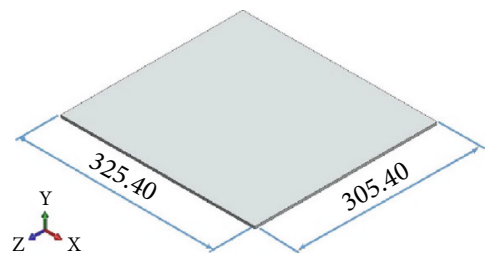

(c)

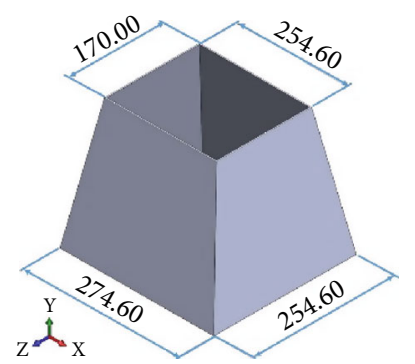

(b)

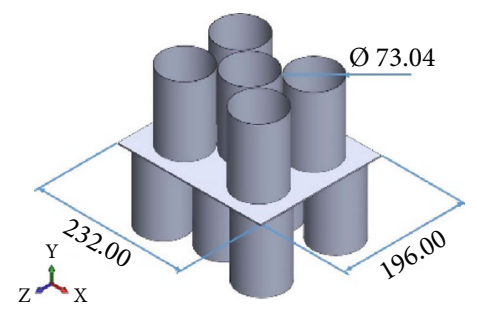

(d)

FIgURE 14: Impact attenuator components: (a) pounder, (b) shell of impact attenuator, (c) buffer component, and (d) food cans arrangement.

found that both curve patterns have dissimilar patterns, the error between them is low.

The comparison of the internal energy between used cans and the impact attenuator is illustrated in Table 1. We found that the proposed finite element simulation agrees well with the experimental test, with minor differences below $5 \%$. The error percentage of the internal energy in used cans is $1.3 \%$ and that of the impact attenuator is $0.2 \%$. We found that, with a reasonable $1-4 \mathrm{~h}$ operating time, these proposed models and analysis methods can be used in the future to repeat designs to quickly achieve the desired impact attenuator.

6.3. Mesh Convergence Study. Mesh convergence is an essential factor in achieving accurate results with reasonable computational time $[35,36]$. The use of a coarse mesh can yield a less-stiff structure response. Therefore, several mesh sizes are used to obtain the optimum mesh sizes with less computational time. Here, a mesh convergence study was conducted by investigating the crushing force response of both impact 
TABLE 2: Material properties of various materials.

\begin{tabular}{lcccc}
\hline Material parameters & $\begin{array}{c}\text { AISI } 1065 \text { carbon steel } \\
{[37]}\end{array}$ & $\begin{array}{c}\text { Aluminum 6063 } \\
{[38]}\end{array}$ & $\begin{array}{c}\text { Aluminum 1100 } \\
{[39]}\end{array}$ & Aluminum alloy 3004 [40] \\
\hline Density $\left(\mathrm{kg} / \mathrm{mm}^{3}\right)$ & $7.85 \times 10^{-6}$ & $2.77 \times 10^{-6}$ & $2.712 \times 10^{-6}$ & $2.68 \times 10^{-6}$ \\
Young's modulus $(\mathrm{GPa})$ & 200 & 70 & 68.9 & $70-80$ \\
Poisson's ratio (-) & 0.3 & 0.33 & 0.33 & 0.33 \\
Tensile yield strength $(\mathrm{GPa})$ & 0.490 & 0.048 & 0.105 & 0.170 \\
Ult. Tensile strength $(\mathrm{GPa})$ & 0.635 & 0.09 & 0.110 & 0.215 \\
\hline
\end{tabular}

\begin{tabular}{|c|c|c|c|c|c|}
\hline$U_{x}$ & $U_{y}$ & $U_{z}$ & $\operatorname{rot}_{x}$ & $\operatorname{rot}_{y}$ & $\operatorname{rot}_{z}$ \\
\hline 0 & 0 & 0 & 0 & 0 & 0 \\
\hline 0
\end{tabular}

FIgURE 15: Boundary conditions of the FE analysis.

attenuators and used cans using six different element sizes. The mesh sizes in the model were set from coarse to fine mesh. The size of the elements applied for used cans with different ELT ratios was $3 \times 3,3.6 \times 3.6,4.2 \times 4.2,4.8 \times 4.8$, $5.4 \times 5.4$, and $6 \times 6 \mathrm{~mm}$. The element size used for the shell of the impact attenuator was $9 \times 9,10.8 \times 10.8,12.6 \times 12.6$, $14.4 \times 14.4,16.2 \times 16.2$, and $18 \times 18 \mathrm{~mm}$.

Figure 13 compares the crushing force of the impact attenuator and the used cans with different mesh sizes, showing that the smaller the mesh size, the higher the crushing force. For detailed analysis, the crushing force for each mesh size was converted to mean force to choose the optimum mesh size. The mean forces for the shell of the impact attenuator with element sizes of $9 \times 9$ and $10.8 \times 10.8 \mathrm{~mm}$ were not significantly different (only about $2.33 \%$ ); as such, we found that an element size of $10.8 \times 10.8 \mathrm{~mm}$ can be used to model the impact attenuator's shell to speed up the computation time while ensuring results accuracy. The mesh convergence test in used cans revealed that the mean forces with element sizes of $3 \times 3$ and $3.6 \times 3.6 \mathrm{~mm}$ were not significantly different (only $1.29 \%$ ), so that the element size of $3.6 \times 3.6 \mathrm{~mm}$ was the best option to numerically model the used cans. From that result, we found these mesh sizes validated the correctness of the model used in this analysis.

\section{Extended Comparative Study: FE Setting and Preparation}

7.1. Geometrical Design and Applied Material. With the extended numerical simulation, we aimed to comparatively design impact attenuators under various scenarios. In this study, four parts were designed: the pounder, the skin of impact attenuator, food cans, and a support/buffer component. In this case, the impact attenuator was subjected to
TABLE 3: Designed scenario variations for the impact attenuator.

\begin{tabular}{lccc}
\hline Velocity & Material types & Slope (degree) & Code \\
\hline & & 0 & A110 \\
& Aluminum 1100 & 10 & A111 \\
$1 \mathrm{~mm} / \mathrm{ms}$ & & 20 & A112 \\
& & 0 & A160 \\
& Aluminum 6063 & 10 & A161 \\
& & 20 & A162 \\
\hline \multirow{3}{*}{$7 \mathrm{~mm} / \mathrm{ms}$} & Aluminum 1100 & 0 & A710 \\
& & 10 & A711 \\
& & 20 & A712 \\
& Aluminum 6063 & 0 & A760 \\
& & 10 & A761 \\
& & 20 & A762 \\
\hline
\end{tabular}

impact load using a collector plate with a thickness of $10 \mathrm{~mm}$, and the pounder was $305.4 \times 325.4 \mathrm{~mm}$ (length $\times$ width), as shown in Figure 14(a). For the element type, we used a four-nodal Belytschko-Tsay shell element with an element size of $20 \times 20 \mathrm{~mm}$. This collector functions to destroy the impact attenuator at a predetermined speed, so a solid and rigid material is required. AISI 1065 carbon steel was used as the collector plate material, as shown in Table 2.

The shell of the impact attenuator had a height of $232 \mathrm{~mm}$, a thickness of $2 \mathrm{~mm}$, and an angle of $9.13^{\circ}$. The impact shell was modeled using the four-nodal BelytschkoTsay shell element, as shown in Figure 14(b). In this case, the impact attenuator shell was modeled by two different aluminum alloy material series, aluminum 6063 and 1100, as shown in Table 2. These are lightweight and easy to shape 


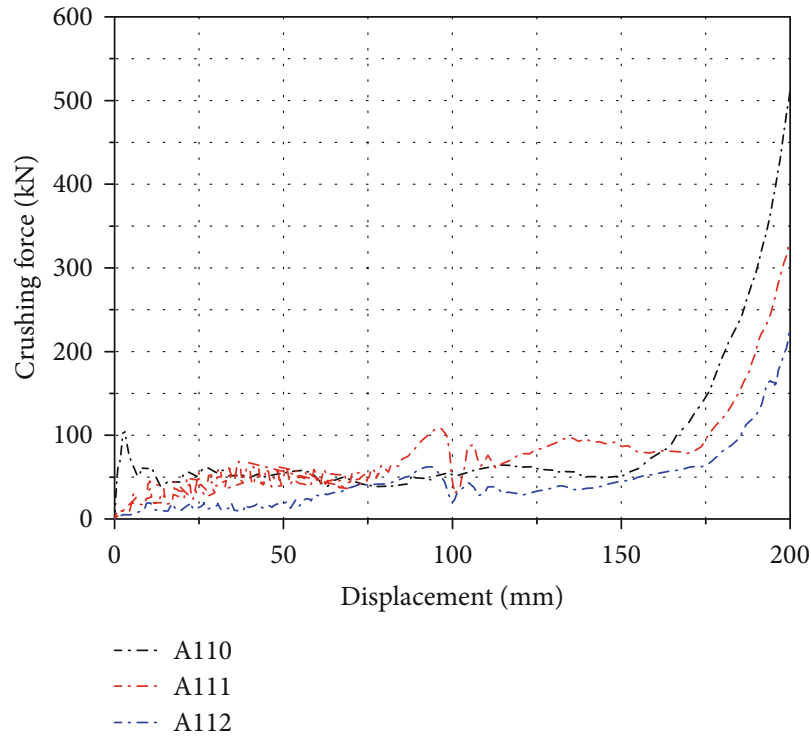

(a)

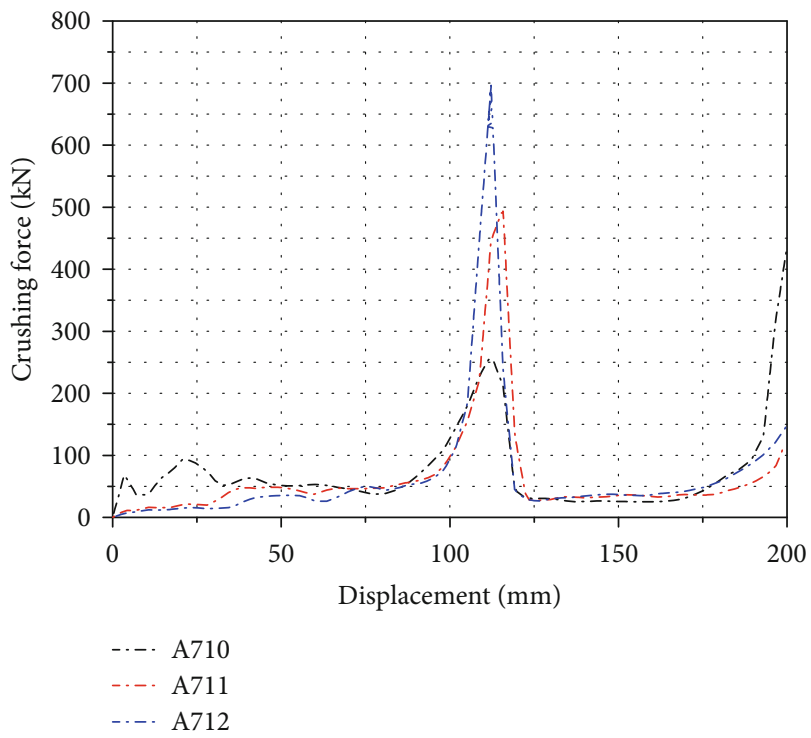

(c)

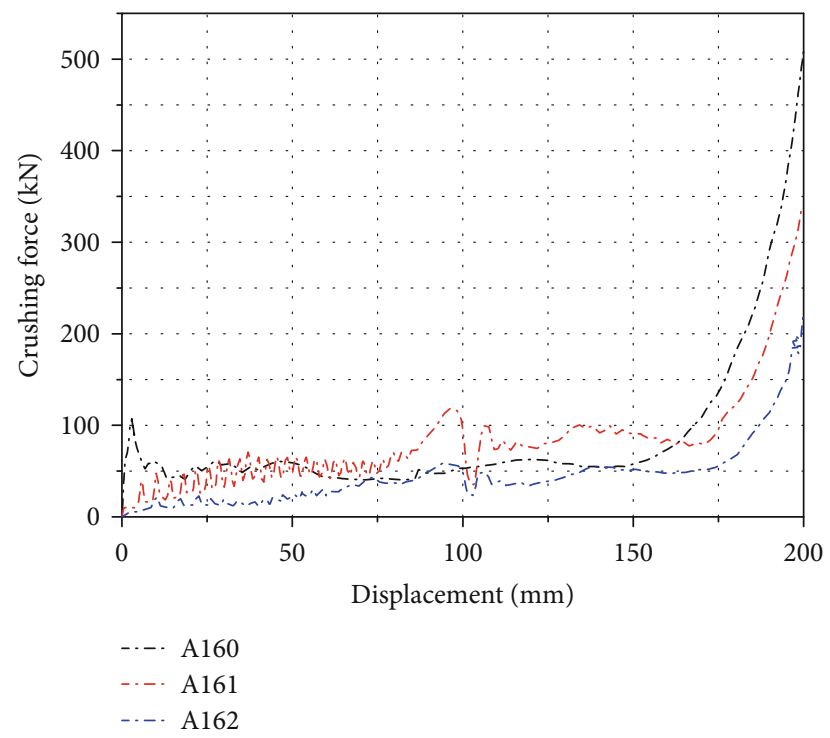

(b)

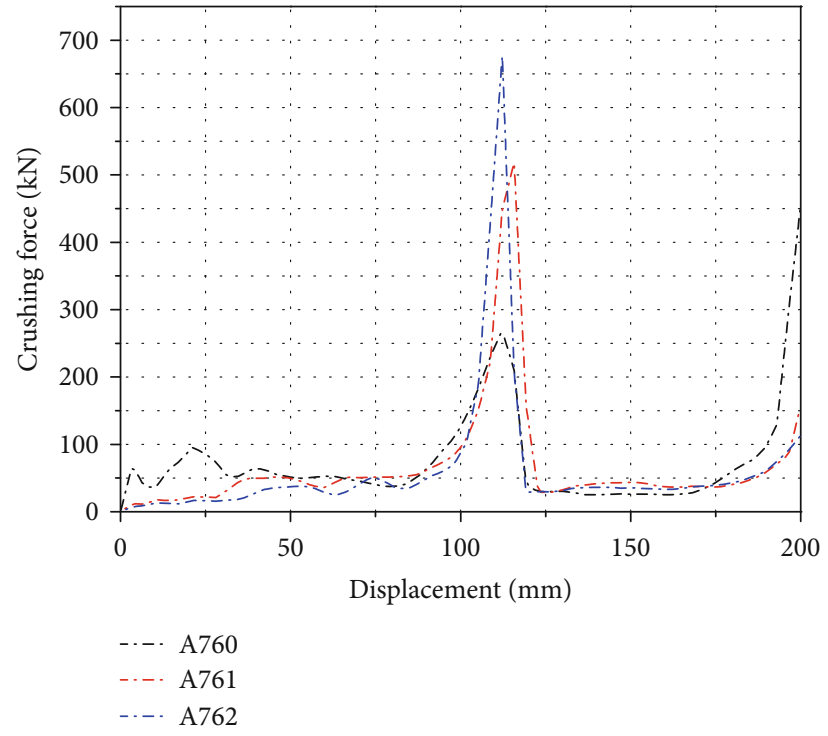

(d)

Figure 16: The crushing force of codes (a) A110, A111, and A112; (b) A160, A161, and A162; (c) A710, A711, and A712; and (d) A760, A761, and A762.

and process. The model material was used using piecewise linear plasticity. The geometrical arrangement of food cans is depicted in Figure 14(d). Food cans were modeled with four nodal Belytschko-Tsay shell elements with a thickness of $0.6 \mathrm{~mm}$ without a lid. The material for used food cans in this test was aluminum alloy 3004 (Table 2) with mechanical properties determined through experiments then validated through simulations with an error below 5\%. The buffer component was modeled as a rigid plate with a thickness of $4 \mathrm{~mm}$, as depicted in Figure 14(c). The buffer dimension of $305.4 \times 325.4 \mathrm{~mm}$ was modeled by the four-nodal Belytschko-Tsay shell. The buffer functioned as a retaining wall for the high-speed impact attenuator. It was modeled by solid and rigid material using AISI 1065 material. The mechanical properties are shown in Table 2.
TABLE 4: Average crushing force for all scenario codes.

\begin{tabular}{lccc}
\hline Scenario code & $\begin{array}{c}\text { Average force } \\
(\mathrm{kN})\end{array}$ & Scenario code & $\begin{array}{c}\text { Average force } \\
(\mathrm{kN})\end{array}$ \\
\hline A110 & 87.0496 & A710 & 75.2296 \\
A111 & 79.2909 & A711 & 63.2848 \\
A112 & 43.9938 & A712 & 66.0406 \\
A160 & 85.3031 & A760 & 75.3592 \\
A161 & 82.3046 & A761 & 66.9697 \\
A162 & 44.1985 & A762 & 60.8248 \\
\hline
\end{tabular}




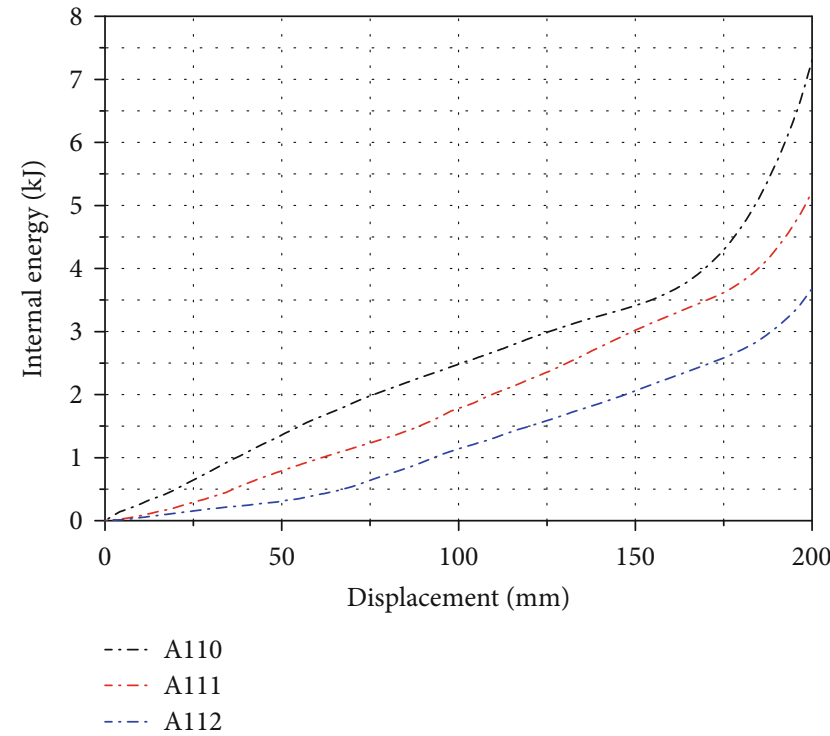

(a)

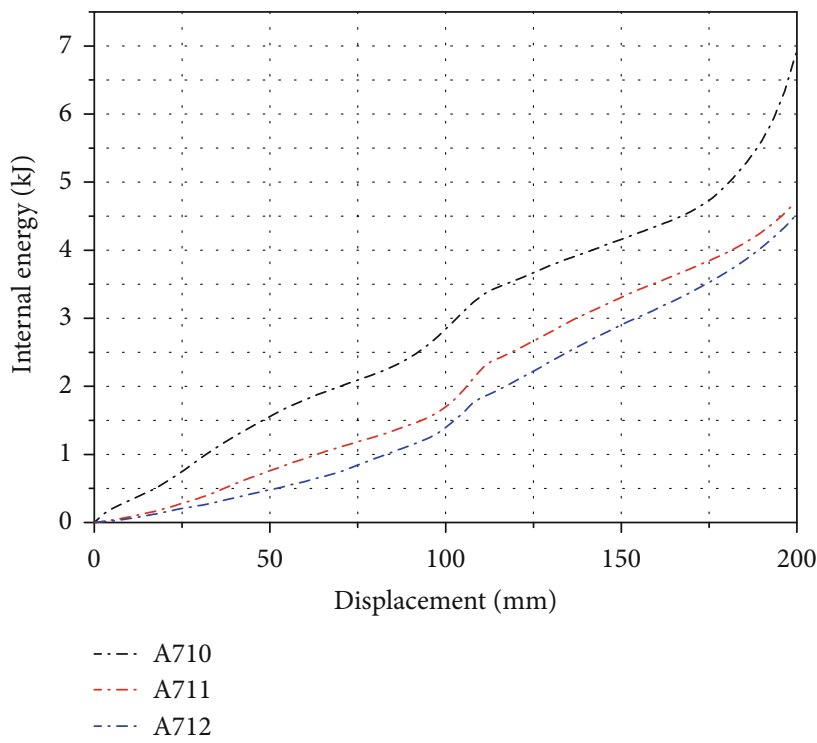

(c)

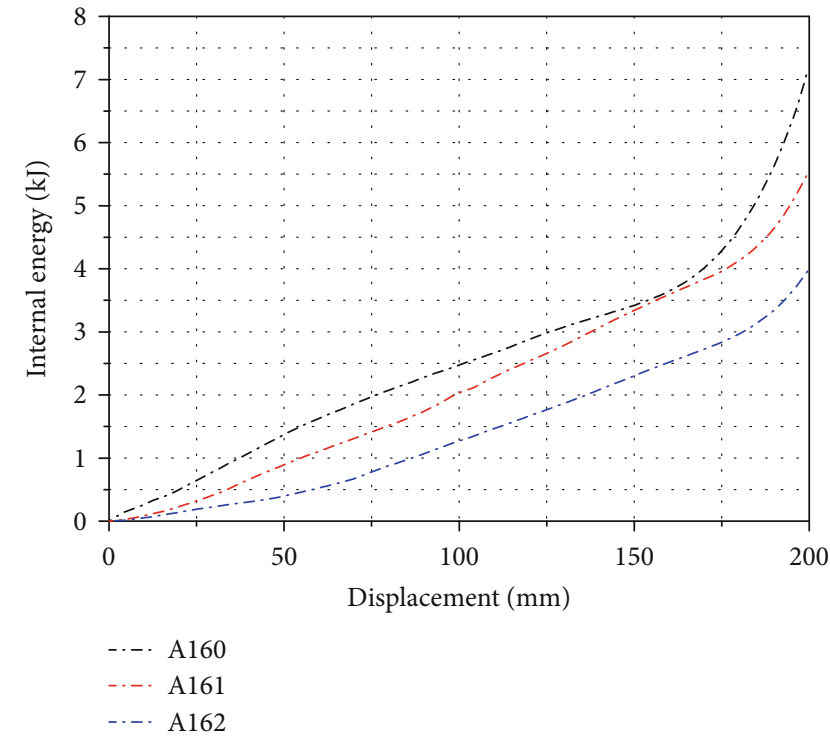

(b)

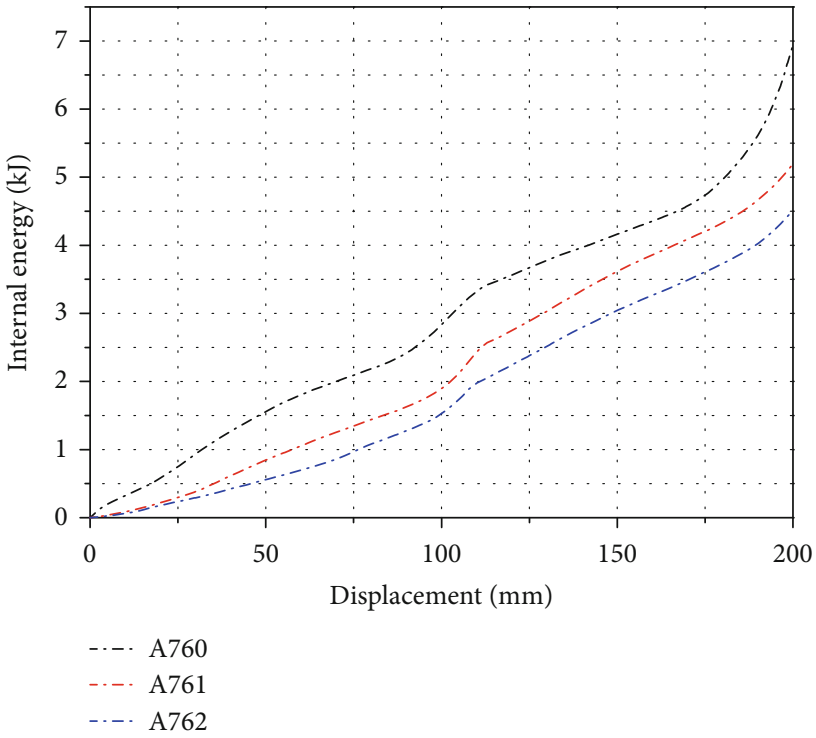

(d)

Figure 17: Internal energy of codes (a) A110, A111, an A112; (b) A160, A161, and A162; (c) A710, A711, and A712; and (d) A760, A761, and A762.

7.2. Boundary Conditions and Impact Scenario. As explained in the JSAE rules, the impact attenuator must be arranged at the front of the car, then crashed into a rigid wall with a constant speed of $7 \mathrm{~m} / \mathrm{s}$ with a car mass of $300 \mathrm{~kg}$ and absorbing $7350 \mathrm{~J}$. In this case, to simplify and shorten the simulation time, the test was arranged as follows: We assumed that the collector moved at a predetermined speed toward the impact attenuator ( $z$-axis), a fixed condition for all rotations and translations on the $\mathrm{X}$ and $\mathrm{Y}$ axes. The buffer was assumed to be in the all degrees of freedom (all DOF) condition, where the rotation and translation on the $\mathrm{X}, \mathrm{Y}$, and $\mathrm{Z}$ axes were in a fixed state, as shown in Figure 15. For this simulation, two types of testing were conducted. The first was testing with quasi-static and dynamic analyses. For
TABLE 5: Internal energy data of all scenario codes.

\begin{tabular}{lccc}
\hline $\begin{array}{l}\text { Scenario } \\
\text { code }\end{array}$ & $\begin{array}{c}\text { Internal energy } \\
(\mathrm{kJ})\end{array}$ & $\begin{array}{c}\text { Scenario } \\
\text { code }\end{array}$ & $\begin{array}{c}\text { Internal energy } \\
(\mathrm{kJ})\end{array}$ \\
\hline A110 & 7.3141 & $\mathrm{~A} 710$ & 6.9315 \\
A111 & 5.2187 & $\mathrm{~A} 711$ & 4.7318 \\
A112 & 3.6821 & $\mathrm{~A} 712$ & 4.5311 \\
A160 & 7.2437 & A760 & 6.9422 \\
A161 & 5.5654 & A761 & 5.1948 \\
A162 & 4.0038 & A762 & 4.5119 \\
\hline
\end{tabular}




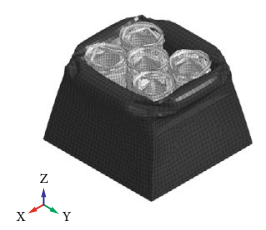

(a)

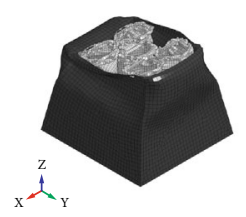

(a)

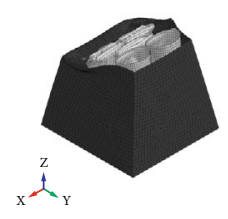

(a)

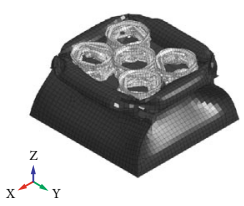

(b)

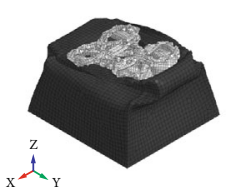

Slope degree $10^{\circ}$

(b)
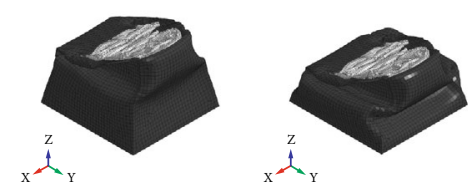

(c)

(c)

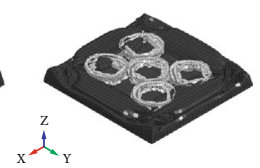

(d)
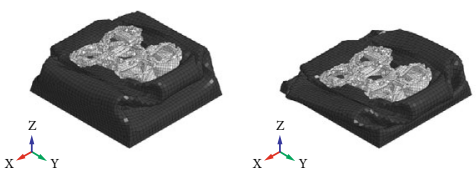

(d)

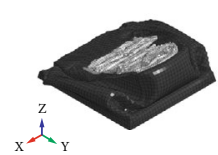

(d)

Figure 18: Deformation shape on various slope degree at displacements of: (a) 50, (b) 100, (c) 150, and (d) $200 \mathrm{~mm}$.

quasi-static analysis, the pounder speed was set to $1 \mathrm{~mm} / \mathrm{ms}$. For dynamic testing, the rate was $7 \mathrm{~mm} / \mathrm{ms}$ according to the JSAE rules. Then, the displacement of the pulverizer was limited to a distance of $200 \mathrm{~mm}$. In this modeling, two types of contact were used: automatic node to the surface and automatic single surface. Automatic node-to-surface contact was used on the surface of a part that contacted another part of the body. In this case, it was used to contact the collector with the impact attenuator and the impact attenuator with the support. This type of contact in LS-DYNA is suitable for use in contacts involving rigid objects based on the information. The automatic single-surface contact type was used to apply interaction with the tube walls. This type of contact interaction prevents the penetration between the folds as the tube undergoes progressive buckling. Based on the description of this type of contact, LS-DYNA is suitable for applications in crashworthiness analysis.

The termination time is the time needed to determine the total time in the test analysis. In this case, two variations in the speed type in the simulation modeling were used to set the time to stop the analysis. At the speed of $1 \mathrm{~mm} / \mathrm{ms}$, the end time was $200 \mathrm{~ms}$, and for $7 \mathrm{~mm} / \mathrm{ms}$, the end time was set to $28.5 \mathrm{~ms}$. The velocity in these two tests was always constant. Without any acceleration or deceleration effect, it was expected to provide deformation and displacement at an impact of $200 \mathrm{~mm}$. In this scenario, various design cases were constructed based on the various velocities, material types, and degrees of slope. A total of 12 codes shown in Table 3 were comprehensively analyzed to obtain the absorption performance.

\section{Structural Crashworthiness: Toward a New Attenuator Design}

8.1. Absorption Performance. After verifying the test results, a pre-processing stage to set the boundary conditions and material properties was applied to the following cases, including performing simulations based on predetermined variations. In this section, the absorption performance results of our new impact attenuator design with different material properties subjected to various impact speed rates and load degrees are provided. Figure 16 compares the crushing force for all predetermined variations. The first is the crushing force curves of code A110, A111, and A112, as shown in Figure 16(a). At the beginning of the displacement, the force curve of A110 has the highest increase compared to the other two curves, with a value of more than 100 $\mathrm{kN}$. This was caused by the collector on the A110 with a slope at 0 degrees that was not tilted or perpendicular to the impact attenuator's axial direction. We also found that the increase in slope decreased the crushing force. If we examine the pattern of the three curves, all three have a pattern that is almost similar to A110's curve, where the highest crushing force was found for A110 and the lowest for A112.

The same phenomenon was observed in the result of crushing force for A160, A161, and A162 (Figure 15(b)), where the curves have patterns and conditions similar to those of A110, A111, and A112. We found that A160 had the highest value, and followed A161, and the lowest was found for A162. Increasing the degree of slope tended to decrease the crushing force. Comparing the crushing force data for A160, A161, and A162 using Aluminum 1100, we 


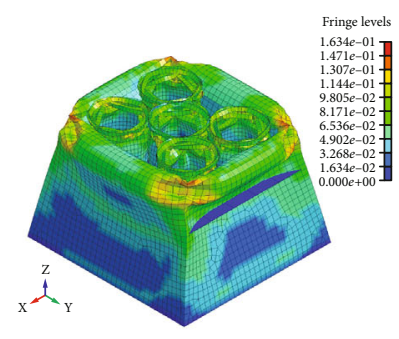

(a)

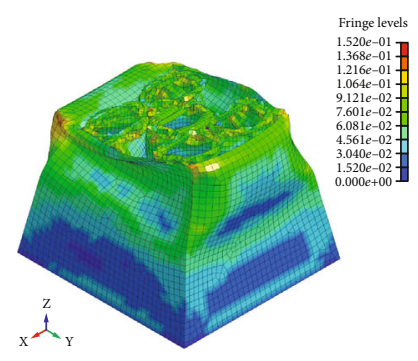

(a)

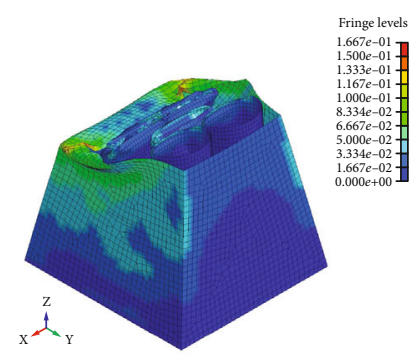

(a)
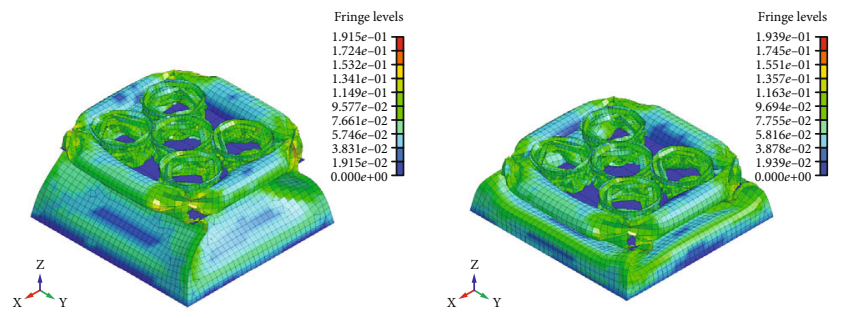

Slope degree $0^{\circ}$

(b)

(c)

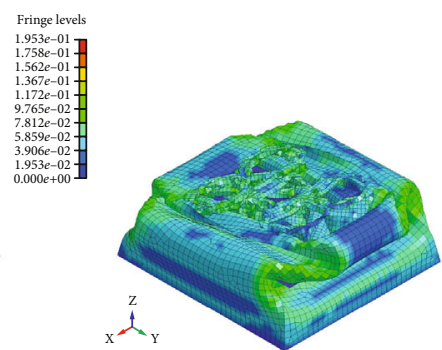

Slope degree $10^{\circ}$

(b)

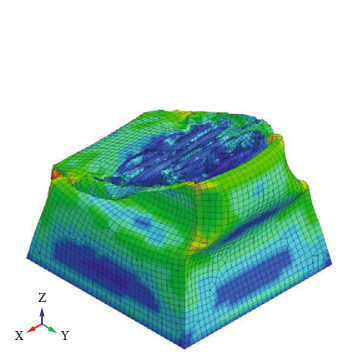

(b)

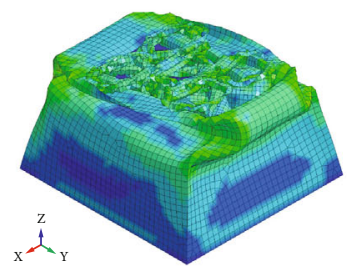

Slope degree $20^{\circ}$
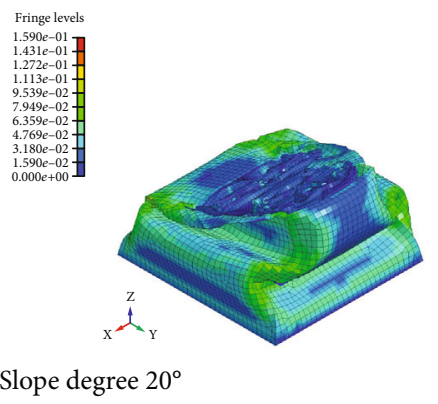

(c)

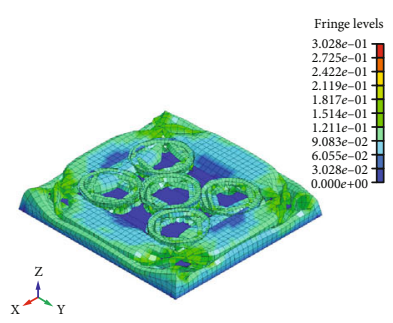

(d)

Figure 19: The von Mises stress at various slope degrees for displacements of (a) 50, (b) 100, (c) 150, and (d) 200 mm.

found that the absolute value of the force curve of A160 reached a maximum load of $500 \mathrm{kN}$, which is higher than that of A110. In detail, the average load values in Table 4 of A110, A111, and A112 at the same slope degree tend to be smaller than those of A160, A161, and A162. From that result, we found that the mechanical properties of the aluminum 6063 series are better than those of the aluminum 1100 series. The highest average value was found in the pounder with a slope of $0^{\circ}$, followed by $10^{\circ}$ and $20^{\circ}$.

The dynamic analysis of the impact load of the proposed impact attenuator design with a speed of crushing force of $7 \mathrm{~mm} / \mathrm{ms}$ is depicted in Figures 16(c) and 16(d). The curves of crushing force of the two materials show a similar pattern. A similar phenomenon also occurred where the higher the slope degree, the lower the crushing force. The data of average load in Table 4 also show that aluminum 6063 series is superior. Compared to the curve pattern with a velocity of $1 \mathrm{~mm} / \mathrm{ms}$, the curve with a rate of $7 \mathrm{~mm} / \mathrm{ms}$ shows a relatively increased load at a displacement of $100 \mathrm{~mm}$. This was caused by the pounder pressing the cans on the bottom layer until deformation occurred. This high load increase was caused by the high impact speed of $7 \mathrm{~mm} / \mathrm{ms}$.

The graph and the final value of internal energy for all model variations are provided in Figure 17 and Table 5, respectively. After the data on the final value of the internal energy were collected, we found that the variation in the impact attenuator with a slope degree of $0^{\circ}$ had the highest internal energy value, followed by $10^{\circ}$ and $20^{\circ}$. This occurred where the collector at an angle of $0^{\circ}$ hit the impact attenuator, perfectly perpendicular to the axial direction. We also found that the models with aluminum 6063 series for all speed and slope variations had almost a better result compared to the model using aluminum 1100, as shown in Table 5. Compared to the impact energy of the model scenario at a speed rate of $7 \mathrm{~mm} / \mathrm{ms}$, at an impact speed of $1 \mathrm{~mm} / \mathrm{ms}$, the energy absorption was better. From this result, we concluded that the slower the impact speed rate, the more the energy absorbed. As technical note, the force is generated to energy, but not solely internal energy. They can be internal energy, kinetic energy, contact (sliding) 


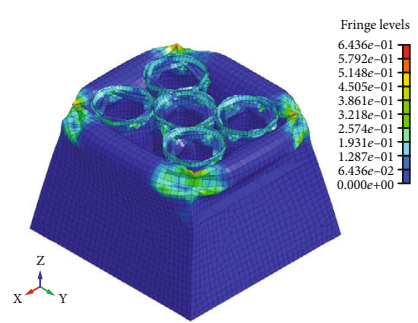

(a)

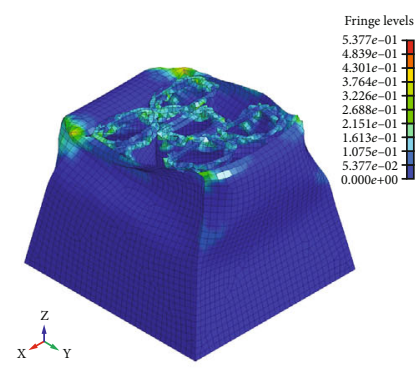

(a)

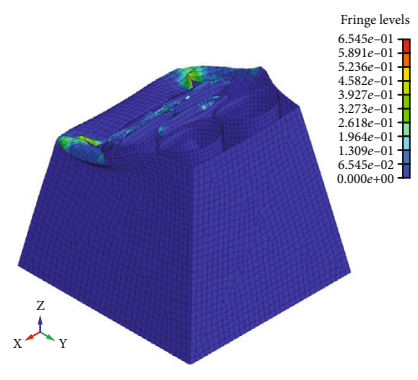

(a)

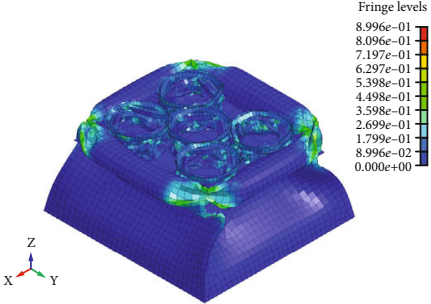

At slope degree $0^{\circ}$

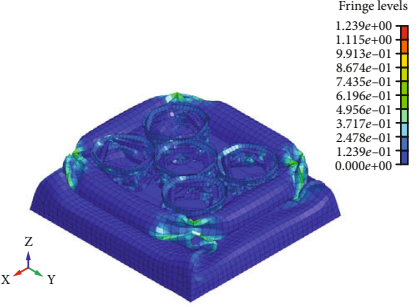

(c)

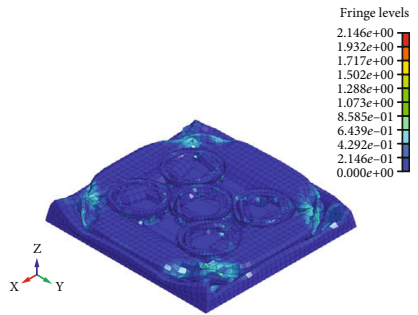

(d)

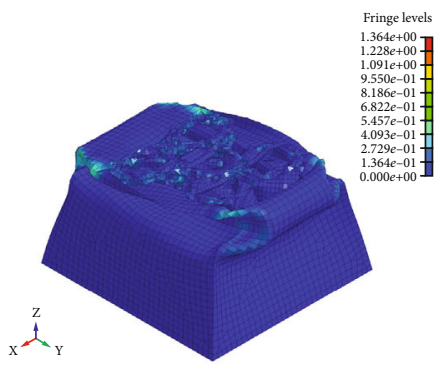

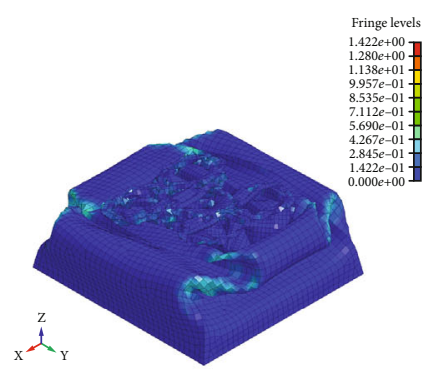

(c)

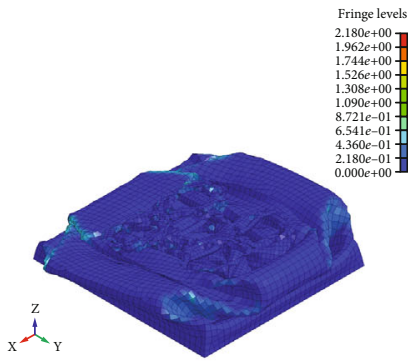

(d)
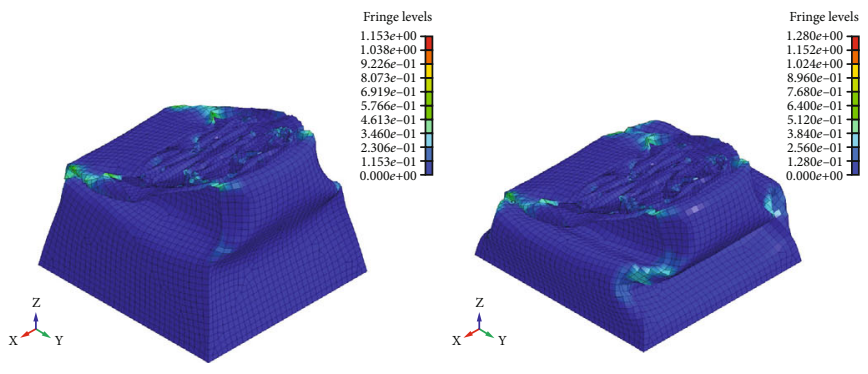

(c)

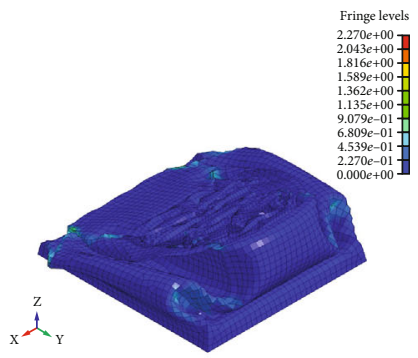

(d)

FIgURE 20: Plastic strain for various slope degrees at displacements of (a) 50, (b) 100, (c) 150, and (d) $200 \mathrm{~mm}$.

energy, hourglass energy, etc. Therefore, value of the crushing force multiplied by displacement will not exactly same as the internal energy.

8.2. Geometrical Failure. After investigating the absorption performance of the impact attenuator due to impact load at a rate of $7 \mathrm{~mm} / \mathrm{ms}$ by comparing the values of crushing force and internal energy of all the evaluated models, we also investigated the behavior and pattern of the geometrical failure under various tilt angles. Several geometrical failures from ANSYS LS-DYNA software, including deformation shape, von Mises stress, and plastic strain, were evaluated.

Figure 18 shows the deformation results of the impact attenuator with a slope angle of $0^{\circ}, 10^{\circ}$, and $20^{\circ}$, analyzed at four stages of displacement: 50, 100, 150, and $200 \mathrm{~mm}$. At an initial displacement of $50 \mathrm{~mm}$, the top part of the cans and the impact attenuator shell began to experience deformation at all slope degrees. At $100 \mathrm{~mm}$, the skin of the impact attenuator began to crease on all sides, experiencing severe damage compared to the displacement at $50 \mathrm{~mm}$. At a displacement of $150 \mathrm{~mm}$, the can at the bottom started to deform, and it wholly deformed at the displacement of
$200 \mathrm{~mm}$. Comparing the deformation shapes at different tilt angles, we found that the model subjected to a $0^{\circ}$ tilt angle experienced the highest deformation. In the impact attenuator design with tilt angles of $10^{\circ}$ and $20^{\circ}$, the deformation pattern showed that the upper part of the impact attenuator experiences different deformation shapes: on the left, it is highly deformed; on the right side, it did not undergo severe deformation. We determined that this $f$ was caused by the entire model not experiencing deformation due to the f tilt angle on the impact attenuator pounder.

In addition to the displacement shape, we also compared the stress and strain. The red color of the fringe levels in Figure 19 shows the maximum stress values in GPa. Therefore, in both contour displays, the red color in the fringe levels represents the most vulnerable parts of the simulated contour, whereas the blue color represents the most durable parts. We found that the vulnerable part due to high stress concentration was experienced in the top corner of the impact attenuator shell. From the stress results of the tilt angle variations, the impact attenuator design subjected to load at $0^{\circ}$ experienced high red contour compared to the other two variations in load angle. 
Based on the contour of the effective plastic strain, we observed that the impact attenuator was subjected to considerable strain on some sides, as shown in Figure 20. This situation is denoted in red, which indicates that the element experienced significant strain. The red tends to be concentrated in the corners of the impact attenuator's skin where the welds were located.

\section{Conclusions}

The structural crashworthiness of a new attenuator design with various predetermined parameters was numerically investigated to determine its absorption and deformation pattern. The verification test of the impact attenuator and used cans showed that both the experimental and numerical results are in good agreement, indicating the correctness of the proposed finite element model with minor differences or error below $5 \%$. A convergence study was conducted to determine the optimal element size used for modeling the cans and impact attenuator shell with a reasonable computational time. From the result, the following conclusions were drawn.

The compressive stimulation test was performed on 12 variations of the impact attenuator. The data were collected to compare and analyze the deformations at three different collision angles and two speed rates. Based on the results, we found that design models using aluminum 6063 series have better mechanical properties. We also found that the $0^{\circ}$ loading angle had the highest absorption capacity, but the higher the slope degree, the lesser the damage. To summarize, we concluded that the model of code A110 had the highest crushing force and internal energy at $87.0496 \mathrm{kN}$ and $7.3141 \mathrm{~kJ}$, respectively. Although the design has not yet reached $7350 \mathrm{~J}$ (obtained highest energy equals with $7314.1 \mathrm{~J}$ ), using waste cans as the impact attenuator might be an alternative to reduce costs compared to other materials, which are expensive and challenging to create. In future research, investigation is needed to obtain higher crashworthiness performance using other used cans with different material compositions.

\section{Nomenclatures}

$\begin{array}{ll}\alpha: & \text { Defined by Equation (10) } \\ \beta: & \text { Aspect ratio } \\ \gamma: & \text { Mass ratio } \\ \varepsilon_{v}: & \text { Tension strain in the upper fibre of the web } \\ \Delta t_{t}: & \text { Difference in time of at time } t \text { compared to the } \\ & \text { initial/selected condition } \\ \delta: & \text { Displacement } \\ \mu: & \text { Mass per unit surface area } \\ \sigma_{0}: & \text { Yield stress } \\ \tau: & \text { Stress tensor } \\ \tau_{v}: & \text { von Mises stress } \\ \sigma_{n}: & \text { Internal stress } \\ \Omega: & \text { Solid volume } \\ \partial \dot{w} / \partial r: & \text { Angular velocity } \\ A: & \text { Surface area } \\ a_{t}: & \text { Acceleration }\end{array}$

\begin{tabular}{|c|c|}
\hline$b:$ & Length \\
\hline $2 B:$ & Width of a rectangular plate \\
\hline$B^{T}:$ & $\begin{array}{l}\text { Form identical to the linear discrete } \\
\text { strain-displacement matrix }\end{array}$ \\
\hline CFE: & Crushing Force Efficiency \\
\hline$d:$ & Diameter of projectile \\
\hline$D_{l}:$ & Plastic energy absorbed \\
\hline$E_{m 1}:$ & Membran energy rate \\
\hline$E A:$ & Energy absorption \\
\hline$F:$ & Crushing force \\
\hline$F^{c o n t}:$ & Contact force \\
\hline$F_{c o n}:$ & Concertina tearing force \\
\hline$F_{t}^{\text {ext }}$ & Applied external and body force vector \\
\hline$F^{h g}:$ & Hourglass resistance force \\
\hline$F_{t}^{\text {int }}:$ & Internal force vector \\
\hline$F_{m}:$ & Mean crushing \\
\hline$G:$ & Impact mass \\
\hline$H:$ & Height of web \\
\hline $2 H:$ & Crushing distance \\
\hline$k:$ & Constant value \\
\hline$k_{r}:$ & Radius changes of curvature \\
\hline 2L: & Length of a rectangular plate \\
\hline$l:$ & Length \\
\hline$m:$ & Mass \\
\hline$M_{0}:$ & Plastic collapse moment per unit length $\left(\sigma_{0} H^{2} / 4\right)$ \\
\hline$M_{\theta}, M_{r}:$ & $\begin{array}{l}\text { Radial and circumferential bending moments per } \\
\text { unit length }\end{array}$ \\
\hline$N_{\theta}, N_{r}:$ & $\begin{array}{l}\text { Radial and circumferential membrane forces per } \\
\text { unit length }\end{array}$ \\
\hline Pm: & Mean crushing force \\
\hline$P$ max: & Peak crushing force \\
\hline$R:$ & Radius \\
\hline$R_{c}:$ & Specific work of fracture \\
\hline SEA: & Specific Energy Absorption \\
\hline$S_{y}:$ & Simple tension elastic limit \\
\hline$T:$ & Response time \\
\hline$t:$ & Time \\
\hline$U_{t}:$ & Displacement at time $t$ \\
\hline$V_{0}:$ & Initial impact or impulsive velocity \\
\hline$V_{t}:$ & Velocity at time $t$ \\
\hline$w:$ & Transverse displacement \\
\hline$W:$ & Transverse displacement at the centre of a plate \\
\hline$W_{f}:$ & Maximum permanent transverse displacement \\
\hline$X_{0}:$ & Initial geometry initial geometry \\
\hline$X_{t}:$ & Updated geometry at time $t$ \\
\hline$x, y:$ & Cartesian coordinates. \\
\hline
\end{tabular}

\section{Data Availability}

The authors declare that the data supporting the findings of this study are available within the article.

\section{Conflicts of Interest}

The author(s) declare(s) that they have no conflicts of interest. 


\section{Acknowledgments}

This work was supported by the RKAT PTNBH Universitas Sebelas Maret, Surakarta under Scheme of "Penelitian Unggulan UNS" (PU-UNS) - Year 2021, with Grant/ Contract No. 260/UN27.22/HK.07.00/2021. The support is gratefully acknowledged by the authors.

\section{References}

[1] SAE International Formula SAE Rules, "SAE international, Pennsylvania," United States, vol. 2018, 2019.

[2] H. Zarei and M. Kröger, "Optimum honeycomb filled crash absorber design," Materials and Design, vol. 29, no. 1, pp. 193-204, 2008.

[3] G. Belingardi and J. Obradovic, "Design of the Impact Attenuator for a formula student racing car: numerical simulation of the impact crash test," Journal of the Serbian Society for Computational Mechanics, vol. 4, no. 1, pp. 52-65, 2010.

[4] R. Munusamy and C. Barton, "Lightweight impact crash attenuators for a small formula SAE race car," International Journal of Crashworthiness, vol. 15, no. 2, pp. 223-234, 2010.

[5] A. R. M. Nazim, M. N. M. Ansari, and A. Atiqah, "Impact strength and morphological properties of Kenaf/glass fibre/polyester hybrid composite for attenuator application," Materials Today: Proceedings, vol. 29, no. 1, pp. 119-122, 2020.

[6] Z. Li, J. Zhang, K. Zhang, L. Zhu, X. Lu, and Z. Huang, “The frontal response of a Spaceframe chassis Sportscar," Proceedings of the Institution of Mechanical Engineers, Part D: Journal of Automobile Engineering, vol. 214, no. 8, pp. 865-873, 2014.

[7] S. Heimbs and F. Strobl, "Crash Simulation of an F1 Racing Car Front Impact Structure," in in 7th Eur. LS-DYNA Conference, pp. 1-8, Salzburg, Austria, 2009.

[8] S. Boria, S. Pettinari, F. Giannoni, and G. Cosimi, "Analytical and numerical analysis of composite impact attenuators," Composite Structures, vol. 156, pp. 348-355, 2016.

[9] H. Borah and U. Dutta, Trends in Beverage Packaging, Tezpur University, Tezpur, India, 2019.

[10] T. Filippini, S. Tancredi, C. Malagoli et al., "Aluminum and tin: Food contamination and dietary intake in an Italian population," Journal of Trace Elements in Medicine and Biology, vol. 52, pp. 293-301, 2019.

[11] H. A. Zamani, M. Ranjkesh, M. R. Abedi, and S. Meghdadi, "Al3+-selective P.V.C. membrane sensor based on newly synthesised 1,4-bis[o-(pyridine-2-carboxamidophenyl)]-1,4-dithiobutane as neutral carrier," International Journal of Electrochemical Science, vol. 9, no. 11, pp. 6495-6504, 2014.

[12] S. Boria, A. Scattina, and G. Belingardi, "Axial crushing of metal-composite hybrid tubes: experimental analysis," Procedia Structural Integrity, vol. 8, pp. 102-117, 2018.

[13] D. Rising, J. Adkins, and C. Hoff, Analysis of a Frontal Impact of a Formula SAE Vehicle, SAE Technical Paper, 2006.

[14] D. Williams, A. Pennington, and C. Barton, "The frontal impact response of a Spaceframe chassis Sportscar," Proceedings of the Institution of Mechanical Engineers Part D Journal of Automobile Engineering, vol. 214, no. 8, pp. 865-873, 2000.

[15] J. Obradovic, S. Boria, and G. Belingardi, "Lightweight design and crash analysis of composite frontal impact energy absorbing structures," Composite Structures, vol. 94, no. 2, pp. 423430, 2012.
[16] Q. Q. Li, E. Li, T. Chen, L. Wu, G. Q. Wang, and Z. C. He, "Improve the Frontal Crashworthiness of Vehicle Through the Design of Front Rail," Thin-Walled Structures, vol. 162, p. 107588, 2021.

[17] G. Balaji and K. Annamalai, "An Experimental and Numerical Scrutiny of Crashworthiness Variables for Square Column with V-Notch and Groove Initiators Under Quasi-Static Loading," Cogent Engineering, vol. 4, no. 1, 2017.

[18] N. Jones and A. Baeder, "An experimental study of the dynamic plastic behavior of rectangular plates," in Proceeding of Symposium on Plastic Analysis of Structures, pp. 476-497, Isai, Rumania, 1972.

[19] Z. Abdullah, M. Sani, S. Salwani, and A. Husain, "A Review on Crashworthiness Studies of Crash Box Structure," ThinWalled Structures, vol. 153, p. 106795, 2020.

[20] N. Hussain, P. Regalla, and D. Rao, "Low velocity impact characterization of glass fiber reinforced plastics for application of crash box," Materials Today: Proceedings, vol. 4, no. 2, pp. 3252-3262, 2017.

[21] N. Jones, S. Kim, and Q. Li, "Response and failure of ductile circular plates struck by a Mass," Journal of Pressure Vessel Technology, vol. 119, no. 3, pp. 332-342, 1997.

[22] A. Reyes and T. Børvik, "Quasi-static behaviour of crash components with steel skins and polymer foam cores," Materials Today Communications, vol. 17, pp. 541-553, 2018.

[23] A. R. Prabowo, S. I. Cahyono, and J. M. Sohn, "Crashworthiness assessment of thin-walled double bottom tanker: A variety of ship grounding incidents," Theoretical and Applied Mechanics Letters, vol. 9, no. 5, pp. 320-327, 2019.

[24] Y. Wang, J. Feng, J. Wu, and D. Hu, "Effects of fiber orientation and wall thickness on energy absorption characteristics of carbon-reinforced composite tubes under different loading conditions," Composite Structutres, vol. 153, pp. 356-368, 2016.

[25] N. Jones, "A theoretical study of the dynamic plastic behavior of beams and plates with finite-deflections," International Journal of Solids and Structures, vol. 7, no. 8, pp. 1007-1029, 1971.

[26] N. Jones, "Literature Review : a literature review of the dynamic plastic response of structures," The Shock and Vibration Digest, vol. 7, no. 8, pp. 89-105, 1975.

[27] N. Jones, Structural Impact, Cambridge University Press, Cambridge, United States, 1989.

[28] N. Jones, "On the mass impact loading of ductile plates," Defence Science Journal, vol. 53, no. 1, pp. 15-24, 2003.

[29] S. Zhang, The Mechanics of Ship Collisions, Technical University of Denmark, Lyngby, Denmark, 1999.

[30] C. Ambrosio, "Dynamic axial crushing," International Centre for Mechanical Sciences, vol. 423, pp. 49-66, 2001.

[31] SimScale, What is von Mises Stress?, 2021, https://bit.ly/ $3 \mathrm{kZ} 5 \mathrm{dZX}$.

[32] A. R. Prabowo and J. M. Sohn, "Nonlinear dynamic behaviors of outer Shell and upper deck structures subjected to impact loading in maritime environment," Curved Layered Structure, vol. 6, no. 1, pp. 146-160, 2019.

[33] A. R. Prabowo, T. Putranto, and J. M. Sohn, "Simulation of The Behavior of a Ship Hull Under Grounding: Effect of Applied Element Size on Structural Crashworthiness," Journal of Marine and Science Engineering, vol. 7, no. 8, p. 270, 2019.

[34] A. R. Prabowo, D. M. Bae, and J. M. Sohn, "Analysis of structural behavior during collision event accounting for bow and 
side structure interaction," Theoretical and Applied Mechanics Letters, vol. 7, no. 1, pp. 6-12, 2017.

[35] A. Tuswan, B. Zubaydi, and A. Piscesa, "Dynamic characteristic of partially debonded sandwich of ferry ro-ro's car deck: a numerical modeling," Open Engineering, vol. 10, no. 1, pp. 424-433, 2020.

[36] T. Tuswan, A. Zubaydi, B. Piscesa, R. C. Ariesta, M. F. Ilham, and F. I. Mualim, "Influence of application of sandwich panel on static and dynamic behaviour of ferry ro-ro ramp door," Journal of Applied Engineering Science, vol. 19, no. 1, pp. 208-216, 2021.

[37] AzoMaterials, A ISI 1065 Carbon Steel (UNS G10650), 2021, https://bit.ly/3x12ba8.

[38] AzoMaterials, Aluminium / Aluminum 6063 Alloy (UNS A96063), 2021, https://bit.ly/2TCQ3yt.

[39] Metalmen, Aluminum 1100 Properties \& Products, 2021, https://bit.ly/314WzI6.

[40] AzoMaterials, Aluminium / Aluminum Alloy 3004 (UNS A93004), 2021, https://bit.ly/3f2kLs6. 